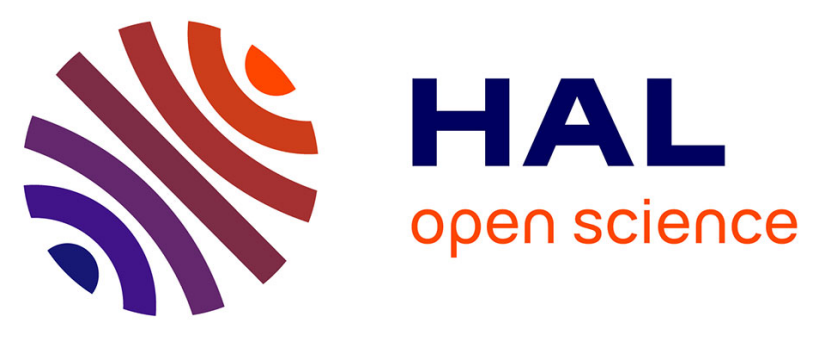

\title{
Physiology and Molecular Biology of Trace Element Hyperaccumulation
}

Sylvain Merlot, Vanesa Sanchez Garcia de La Torre, Marc Hanikenne

\section{To cite this version:}

Sylvain Merlot, Vanesa Sanchez Garcia de La Torre, Marc Hanikenne. Physiology and Molecular Biology of Trace Element Hyperaccumulation. Van der Ent, Antony and Echevarria, Guillaume and Baker, Alan J.M. and Morel, Jean Louis. Agromining: Farming for Metals, Springer International Publishing, pp.155-181, 2021, Mineral Resource Reviews, 978-3-319-61898-2 978-3-319-61899-9. 10.1007/978-3030-58904-2_8. hal-03426699

\section{HAL Id: hal-03426699 https://hal.science/hal-03426699}

Submitted on 12 Nov 2021

HAL is a multi-disciplinary open access archive for the deposit and dissemination of scientific research documents, whether they are published or not. The documents may come from teaching and research institutions in France or abroad, or from public or private research centers.
L'archive ouverte pluridisciplinaire HAL, est destinée au dépôt et à la diffusion de documents scientifiques de niveau recherche, publiés ou non, émanant des établissements d'enseignement et de recherche français ou étrangers, des laboratoires publics ou privés. 


\section{Chapter 8}

\section{Physiology and molecular biology of trace element hyperaccumulation}

Sylvain Merlot, Vanesa S. Garcia de la Torre and Marc Hanikenne

S. Merlot $(\bowtie)$

Université Paris-Saclay, CEA, CNRS, Institute for Integrative Biology of the Cell (I2BC), 91198, Gif-sur-Yvette, France. Email: sylvain.merlot@i2bc.paris-saclay.fr

\section{V.S. Garcia de la Torre}

Université Paris-Saclay, CEA, CNRS, Institute for Integrative Biology of the Cell (I2BC), 91198, Gif-sur-Yvette, France.

\section{Hanikenne}

InBioS-PhytoSystems, Functional Genomics and Plant Molecular Imaging, University of Liège, B4000 Liège, Belgium. 


\begin{abstract}
Metals (trace elements) are essential for plants but become toxic at high concentration. Remarkably, about 700 species worldwide are able to accumulate large quantities of metals in their leaves and are therefore called metal hyperaccumulators. In the context of sustainable development, there is renewed interest in understanding the mechanisms of metal hyperaccumulation that may become instrumental for improved metal phytoextraction from contaminated soils and for making metals available at lower environmental cost. In addition, studying the molecular mechanisms of hyperaccumulation in diverse plant species is necessary in order to understand the evolution of this extreme and complex adaptation trait in plants. Our current knowledge of metal hyperaccumulation is based mostly on the analysis of few species from the Brassicaceae family and suggests that the underlying mechanisms result from an exaggeration of the basic mechanisms involved in metal homeostasis. However, the development of Next Generation Sequencing technologies enables the study of new hyperaccumulator species and therefore the revealing of greater diversity in these mechanisms. The goal of this chapter is to provide background information on metal hyperaccumulation and give an instantaneous picture of what is currently known about the molecular mechanisms involved in this trait. We also attempt to outline for the reader the future scientific challenges that this field of research is facing.
\end{abstract}




\subsection{Introduction}

Investigating the mechanisms involved in metal hyperaccumulation allows observation of extreme adaptation of the metal homeostasis network in plants and identification of key players in metal distribution and tolerance within plant tissues. The study of metal hyperaccumulator species also allows understanding the genetic mechanisms involved in the evolution of an extreme adaptive trait (Shahzad et al. 2010; Hanikenne and Nouet 2011; Hanikenne et al. 2013). Several comprehensive reviews on metal hyperaccumulation have been published in the past years and we refer interested readers to those reviews (Verbruggen et al. 2009, 2013a; Krämer 2010; Hanikenne and Nouet 2011; Rascio and Navari-Izzo 2011; Ricachenevsky et al. 2015; Van der Pas and Ingle 2019).

Whereas hyperaccumulator species commonly accumulate one metal when growing in their natural environment, some species have the ability to tolerate and accumulate several metals when grown ex situ. The latter case is well documented for the hyperaccumulator species of the Brassicaceae family Noccaea caerulescens, in which serpentine-adapted accessions such as Puy de Wolf, Monte Prinzera, and Puente Basadre are able to accumulate Ni but also Zn and Cd (Peer et al. 2003; Assunção et al. 2003; Escarré et al. 2013; Gonneau et al. 2014; Callahan et al. 2016). This ability to tolerate and accumulate several metals likely reflects the relatively low specificity of some mechanisms involved in metal transport and chelation in plants.

Several metals that are concentrated in hyperaccumulator species (e.g. $\mathrm{Zn}, \mathrm{Ni}, \mathrm{Mn}$ ) are essential nutrients but become toxic at high levels for most plants (i.e. non-accumulating species). Therefore, all plant species have developed mechanisms to regulate essential metal homeostasis according to their needs and metal availability in soils (Burkhead et al. 2009; Thomine and Vert 2013; Ricachenevsky et al. 2015; Shao et al. 2017; Clemens 2019; Kobayashi et al. 2019). Our current knowledge suggests that the molecular mechanisms involved in metal hyperaccumulation essentially derive from the mechanisms involved in metal homeostasis. In several examples, genes involved in metal homeostasis are differentially expressed in hyperaccumulators compared to related, non-accumulator species as a result of gene duplication and/or changes in gene promoter activity (Talke et al. 2006; van de Mortel et al. 2006; Krämer et al. 2007; Hanikenne et al. 2008; Shahzad et al. 2010; Suryawanshi et al. 2016). However, specific genes linked to hyperaccumulation may be discovered as future molecular analyses of hyperaccumulation are extended to additional non-model species from various plant families, thanks to the development of high-throughput DNA sequencing technologies (Verbruggen et al. 2013a; Halimaa et al. 2014b; Merlot et al. 2014; Meier et al. 2018). For most metals, the hyperaccumulation trait appeared independently in distant plant families. Therefore, some of the mechanisms involved in 
metal hyperaccumulation may be specific to a plant family or a species, whereas other mechanisms may be convergent among distant hyperaccumulators. For instance, several examples of convergent evolution have been identified between the Brassicaceae Arabidopsis halleri and Noccaea caerulescens (see below and Krämer et al. 2007; Hanikenne et al. 2008; O'Lochlainn et al. 2011; Craciun et al. 2012), suggesting important functional constraints in the metal homeostasis network.

Because of its singularity, metal hyperaccumulation may appear as an exception with limited relevance. However, from a scientific point of view, metal hyperaccumulation in plants is fascinating, and understanding the mechanisms involved in this trait may provide tools needed in order to extract metals from soil with a lower impact on the environment in the near future. The goal in this chapter is to outline our current knowledge about molecular mechanisms of metal hyperaccumulation in plants and to highlight possible future developments in this field of research.

\subsection{Molecular Physiology of Metal Hyperaccumulation}

\subsubsection{Main steps of metal hyperaccumulation}

When exposed to excess metals, most plant species adopt a so-called excluder strategy to prevent metal accumulation in photosynthetically active shoot tissues (Krämer 2010). This result can be achieved by limiting metal absorption by roots, increasing metal efflux from root tissues, and/or increasing metal storage in root cell walls and vacuoles. In contrast, achieving metal hyperaccumulation and associated (hyper)tolerance requires modifications at specific nodes of the metal homeostasis network to ensure that the metal flux in the plant is directed towards shoot tissues (Figure 8.1; Clemens et al. 2002). At the physiological level, these alterations include some or all of the following steps:

1. An enhanced metal mobilization and uptake in roots;

2. An efficient radial metal transport towards the root vascular tissues. This includes a reduction of metal storage in root vacuoles;

3. An increased transport of metal from the root to the shoot, with efficient xylem loading. This step contributes to metal tolerance by enabling metal storage (and thus detoxification) in shoot tissues;

4. An efficient mechanism for xylem unloading and metal distribution in shoots together with high vacuolar storage capacity. 
In addition, evidence that modifications of the cell wall, which has a large metal-binding capacity (Krzesłowska 2011), is also contributing to knowledge of metal accumulation and tolerance (Meyer et al. 2015; Peng et al. 2017; Corso et al. 2018; Lešková et al. 2019). Further investigations will reveal in detail the role of the cell wall in roots and shoots in achieving metal hyperaccumulation and hypertolerance.

\subsubsection{Metal distribution in shoots}

Metal distribution in shoot tissues is specific to both the species and the metal considered. This topic has been extensively reviewed (Fernando et al. 2013; Leitenmaier and Küpper 2013; van der Ent et al. 2018; Kopittke et al. 2018). Briefly, in most cases, metals ( $\mathrm{Zn}, \mathrm{Cd}$, Ni or Se) accumulate at the basis of the trichomes and in the vacuoles of epidermal cells. In contrast, mesophyll cells that are the main site of photosynthesis accumulate lower quantities of metals (Küpper et al. 1999; Küpper et al. 2001; Lombi et al. 2002; Cosio et al. 2005). In the vacuoles of epidermal cells, metals can reach very high concentrations (e.g. several hundred mM, Küpper et al. 1999; Fernando et al. 2006). There are, however, some exceptions. For instance, $\mathrm{Zn}$ and/or $\mathrm{Cd}$ are stored in the vacuoles of mesophyll cells of the hyperaccumulators Arabidopsis halleri, Noccaea tymphaea and Sedum alfredii, where Zn is mostly bound to malate (Küpper et al. 2000; Sarret et al. 2002, 2009; Tian et al. 2011; Lu et al. 2014; Isaure et al. 2015; van der Ent et al. 2019). A significant amount of $\mathrm{Cd}$ is also found in the vascular tissues of the main vein in leaves of A. halleri ssp. gemmifera (Fukuda et al. 2020). Lead, mostly bound to acetate, accumulates in the epidermis and collenchyma vascular cells of petioles and leaf blades in $A$. halleri ssp. halleri (Höreth et al. 2020). In the hyperaccumulator Sedum plumbizincola, $\mathrm{Zn}$ accumulates mostly in leaf epidermal cells, but also in large amounts in mesophyll cells of young leaves (Cao et al. 2014). In this species, Cd is mostly bound to cell walls in leaves (Peng et al. 2017). Accumulation of $\mathrm{Mn}$ in mesophyll cells is also observed in several Mn hyperaccumulators (Fernando et al. 2006a, b, 2013).

Because it requires access to rare and expensive infrastructures, metal imaging has been, and often still remains, a bottleneck in the characterization of metal hyperaccumulators, and more generally in investigations of metal homeostasis mechanisms in plants. The rapid development of metal imaging technologies, including sample preparation protocols that preserve metal distribution and speciation in tissues, is nonetheless progressively alleviating this bottleneck (van der Ent et al. 2018; Kopittke et al. 2018).

\subsubsection{Identification of molecular actors involved in metal hyperaccumulation}


In the last 15 years, a number of complementary approaches have been used to identify the molecular actors underlying hyperaccumulation and hypertolerance. These approaches include:

1. Screens of cDNA libraries in yeast to isolate genes contributing to metal transport and tolerance (e.g. Bernard et al. 2004; Lasat et al. 2000; Papoyan and Kochian 2004; Pence et al. 2000);

2. Quantitative genetics analyses aiming to identify Quantitative Traits Loci (QTLs) cosegregating with the traits in progenies of crosses between an hyperaccumulator and a related non-accumulator species, or between accessions of a species with contrasting hyperaccumulation and/or tolerance phenotypes (Dräger et al. 2004; Deniau et al. 2006; Courbot et al. 2007; Filatov et al. 2007; Willems et al. 2007, 2010; Frérot et al. 2010; Baliardini et al. 2015; Karam et al. 2019);

3. Transcriptomic studies comparing gene expression levels in hyperaccumulator and related nonaccumulator species or accessions. This approach has benefited more recently from the development of the RNA-Seq technology (Becher et al. 2004; Weber et al. 2004, 2006; Chiang et al. 2006; Talke et al. 2006; van de Mortel et al. 2006, 2008; Craciun et al. 2006; Filatov et al. 2006; Hammond et al. 2006; Gao et al. 2013; Halimaa et al. 2014b, 2019; Milner et al. 2014; Han et al. 2016; Peng et al. 2017; Corso et al. 2018; Garcia de la Torre et al. 2018; Schvartzman et al. 2018).

Candidate genes mostly involved in metal transport, metal chelator synthesis, or metal-induced oxidative stress response were indentified with these approaches. Note that the last category will not be discussed further in this chapter. Several candidate genes were characterized functionally (Pence et al. 2000; Persans et al. 2001; Dräger et al. 2004; Kim et al. 2004; Hanikenne et al. 2008; Gustin et al. 2009; Lin et al. 2009; Shahzad et al. 2010; Ueno et al. 2011; Milner et al. 2012, 2014; Deinlein et al. 2012; Merlot et al. 2014; Baliardini et al. 2015; Nouet et al. 2015; Charlier et al. 2015; Cornu et al. 2015; Ahmadi et al. 2018; Uraguchi et al. 2019). However, only a few candidates (i.e. HMA4, HMA3, $N A S 2$ and $C A X 1)$ were confirmed by reverse genetics in hyperaccumulator species as major players in metal hyperaccumulation and tolerance. Their functions are described in detail in the next sections.

A large part of our knowledge of metal hyperaccumulation comes from the study of two model $\mathrm{Zn}$ and Cd hyperaccumulating species of the Brassicaceae family, A. halleri and N. caerulescens, which are related to the sensitive and non-accumulating species Arabidopsis thaliana (Yogeeswaran et al. 2005; Clauss and Koch 2006). These two species have been instrumental in successfully improving our understanding of the physiological, molecular, and genetic bases of metal hyperaccumulation and 
associated hypertolerance (Krämer et al. 2007; Milner and Kochian 2008; Pauwels et al. 2008; Roosens et al. 2008; Verbruggen et al. 2009, 2013b; Krämer 2010; Hanikenne and Nouet 2011; Honjo and Kudoh 2019). Those successes relied on the availability of the A. thaliana genome sequence (The Arabidopsis Genome Initiative 2000) and dedicated tools and resources combined with relatively high gene sequence conservation among Brassicaceae species: $94 \%$ and $88 \%$ identity with $A$. thaliana for A. halleri and N. caerulescens, respectively (Talke et al. 2006; van de Mortel et al. 2006). It is expected that our knowledge base will rapidly become broader with new species becoming accessible to molecular and genomic analyses (Gao et al. 2013; Verbruggen et al. 2013a; Merlot et al. 2014; Van der Pas and Ingle 2019).

\subsection{Mechanisms of Zinc and Cadmium Hyperaccumulation}

As mentioned above, most of our understanding of $\mathrm{Zn}$ and $\mathrm{Cd}$ hyperaccumulation was acquired using A. halleri and N. caerulescens (Figure 8.2). More recent models include (i) the Crassulaceae Sedum alfredii and Sedum plumbizincola from Asia, which are among the few species reported to hyperaccumulate Cd outside the Brassicaceae (Yang et al. 2004, 2006; Deng et al. 2007; Wu et al. 2013; Cao et al. 2014; Peng et al. 2017; Li et al. 2018); and (ii) the Amaranthaceae Gomphrena claussenii from South America, which is strongly tolerant to $\mathrm{Zn}$ and $\mathrm{Cd}$, and presents indicator levels of $\mathrm{Zn}$ and Cd accumulations (Villafort Carvalho et al. 2013, 2015; Pongrac et al. 2018).

Arabidopsis halleri and N. caerulescens display constitutive $\mathrm{Zn}$ hyperaccumulation and hypertolerance, although intraspecific variation for those traits has been reported (Bert et al. 2000, 2002; Reeves et al. 2001; Assunção et al. 2003; Molitor et al. 2005; Pauwels et al. 2006; Besnard et al. 2009; Stein et al. 2017). Similarly, hyperaccumulation of Cd shows substantial intraspecific variation (Escarré et al. 2000; Bert et al. 2002; Roosens et al. 2003; Verbruggen et al. 2013b; Meyer et al. 2015; Stein et al. 2017). Metal hyperaccumulation has evolved independently in the two species (Krämer 2010). However, both share a set of alterations of their metal homeostasis networks in comparison to the non-accumulator $A$. thaliana, which we detail below.

\subsubsection{Uptake of zinc and cadmium}

Prior to uptake, it is suggested that metals are actively mobilized from the soil, by acidification and/or chelate secretion (Clemens et al. 2002). It was, however, suggested that $A$. halleri roots secrete elevated levels of nicotiniamine (NA), a metal chelator able to form NA-Zn complexes (Curie et al. 2009; Clemens et al. 2013) that may reduce root $\mathrm{Zn}$ uptake and increase tolerance to this metal (Tsednee et al. 2014). Another report indicated higher organic acid levels and $\mathrm{Zn}$ mobilization in the dissolved 
organic matter in the rhizosphere of hyperaccumulator, compared to non-accumulator accessions of Sedum alfredii (Li et al. 2012).

Several divalent metal transporters of the ZIP (Zrt-Irt-like Protein) family are highly expressed in roots and/or shoots of both A. halleri and N. caerulescens (Talke et al. 2006; Krämer et al. 2007; Lin et al. 2009, 2016; Wu et al. 2009). This presumably results in enhanced rates of metal uptake in roots or mobilization from root storage sites. By contributing to $\mathrm{Zn}$ radial transport towards the xylem in roots, it may also contribute to metal partitioning between root and shoot tissues. Several ZIP genes are induced by Zn deficiency under the control of the bZIP19 and bZIP23 transcription factors in $A$. thaliana (Assunção et al. 2010). Their high expression in A. halleri and N. caerulescens roots could be the direct consequence of the high activity of HMA4 (Heavy Metal ATPase 4, see below), which depletes $\mathrm{Zn}$ in roots (Talke et al. 2006; Hanikenne et al. 2008; Gustin et al. 2009). Several ZIP genes are also highly expressed in S. plumbizincola and in S. alfredii hyperaccumulator individuals (Peng et al. 2017; Yang et al. 2018). Recently, intraspecific comparison in both A. halleri and N. caerulescens has revealed that the expression of the ZIP transporter IRT1 (Iron-Regulated Transporter 1) correlates with variation of $\mathrm{Zn}$ and/or $\mathrm{Cd}$ accumulation among populations (Corso et al. 2018; Schvartzman et al. 2018; Halimaa et al. 2019). IRT1 encodes the main Fe-uptake transporter at the root epidermis in A. thaliana (Vert et al. 2002; Thomine and Vert 2013), but because of a low selectivity, it is also responsible for the uptake of additional divalent metal cations such as $\mathrm{Zn}, \mathrm{Cd}$, or $\mathrm{Ni}$ (Korshunova et al. 1999; Vert et al. 2002; Nishida et al. 2011; Barberon et al. 2011, see also Ni section below). Constitutive differences in gene expression and protein levels of IRT1 were linked to differential $\mathrm{Zn}$ and $\mathrm{Cd}$ shoot accumulation among Polish and Italian metalicollous populations of $\mathrm{A}$. halleri (Corso et al. 2018; Schvartzman et al. 2018). Variation of IRT1 expression level, together with altered functionality of the protein, is also observed among two calamine populations of $N$. caerulescens with distinct $\mathrm{Cd}$ accumulation capacity (Halimaa et al. 2019). These later reports suggest that $\mathrm{Zn}$ and $\mathrm{Cd}$ differentially interfere with Fe homeostasis and induce a Fe deficiency response in these $A$. halleri and N. caerulescens populations. The authors also suggest that maintaining Fe homeostasis in key in $\mathrm{Zn}$ and $\mathrm{Cd}$ hyperaccumulators and that alternative strategies evolved to do so among populations.

Further work will be required to determine the individual function of ZIP transporters in hyperaccumulation. The respective contribution of $\mathrm{Zn}$ and/or Fe transport mechanisms to $\mathrm{Zn}$ and $\mathrm{Cd}$ uptake also needs to be thoroughly assessed. Additional studies are required to determine the individual function of ZIP transporters in hyperaccumulation. The respective contribution of $\mathrm{Zn}$ and/or 
Fe transport mechanisms to $\mathrm{Zn}$ and $\mathrm{Cd}$ uptake also needs to be assessed in detail (Meyer and Verbruggen 2012).

\subsubsection{Root-to-shoot transfer of zinc and cadmium}

Increased rate of root-to-shoot metal transfer is key to achieving metal hyperaccumulation in shoots. It requires enhanced radial transport to xylem, decreased vacuolar storage in root cells, and efficient xylem loading. Several $N A S$ (nicotianamine synthase) genes are highly expressed in A. halleri and $N$. caerulescens (Weber et al. 2004; van de Mortel et al. 2006; Deinlein et al. 2012). NAS transcript levels are also higher in roots of a hyperaccumulator accession compared to a non-hyperaccumulator accession in S. alfredii (Liang et al. 2014). Elevated levels of NA have been measured in roots of $A$. halleri compared to A. thaliana (Weber et al. 2004; Deinlein et al. 2012). It was further shown using A. halleri RNAi lines that high expression of the NAS2 gene provides increased NA levels for $\mathrm{Zn}$ symplastic mobility towards the xylem, and for controlling the rate of $\mathrm{Zn}$ xylem loading in roots (Deinlein et al. 2012; Cornu et al. 2015). This process is important in order to enable $\mathrm{Zn}$ hyperaccumulation in plants exposed to a wide range of $\mathrm{Zn}$ availability in the soil (Uraguchi et al. 2019). The concentration of the amino-acid histidine (His) weakly correlates with Zn content in $N$. caerulescens and His was shown to enhance $\mathrm{Zn}$ xylem loading, thus contributing to reduce $\mathrm{Zn}$ storage in roots (Callahan et al. 2007; Kozhevnikova et al. 2014).

In A. halleri, $\mathrm{Zn}$ and Cd loading into the xylem is driven by the HMA4 protein (Talke et al. 2006; Courbot et al. 2007; Hanikenne et al. 2008), which is a plasma membrane P-Type ATPase pump that uses the energy released from the hydrolysis of ATP to transport the metal against the electro-chemical gradient (Hussain et al. 2004; Wong and Cobbett 2009; Pedersen et al. 2012; Hanikenne and Baurain 2014). The HMA4 gene co-segregates with QTLs for Zn and Cd tolerance and accumulation (Courbot et al. 2007; Willems et al. 2007, 2010; Frérot et al. 2010; Meyer et al. 2016). High expression of HMA4 is required for both hyperaccumulation and hypertolerance in A. halleri (Talke et al. 2006; Hanikenne et al. 2008). Increased gene dosage of HMA4 was selected during the evolutionary history of A. halleri, and evolved through tandem triplication and activation in cis of the promoters of all three copies (Hanikenne et al. 2008, 2013). The A. halleri HMA4 locus was shaped by positive selection, resulting in a selective sweep and ectopic gene conversion (Hanikenne et al. 2013). The three HMA4 copies are mainly active in vascular tissues of $A$. halleri, which allows acting in xylem metal loading in roots and possibly in metal distribution in leaves. It may also ensure metal exclusion from metal-sensitive tissues (e.g. root tip, cambium). By controlling highly active Zn xylem loading, HMA4 also acts as a physiological regulator: it depletes the root $\mathrm{Zn}$ pool, which triggers a $\mathrm{Zn}$-deficiency response resulting 
in high expression of several ZIP genes (Hanikenne et al. 2008). In agreement, modeling of the $\mathrm{Zn}$ supply-dependent spatio-temporal evolution of $\mathrm{Zn}$ concentration in root symplast and apoplast of $A$. thaliana predicted that slight changes in HMA4 transcript levels have a major impact on the radial distribution of $\mathrm{Zn}$ in roots and on the root to shoot $\mathrm{Zn}$ gradient (Claus et al. 2013). This result was recently confirmed in $A$. halleri using ${ }^{65} \mathrm{Zn}$ imaging (Kajala et al. 2019). It was further shown that a certain extent of functional differentiation exists among the three AhHMA4 copies when expressed in A. thaliana, stemming from differences in expression levels rather than in expression profiles. Interestingly, AhHMA4 copy 3 was subjected to the strongest, possibly most recent, positive selection during the evolutionary history of $A$. halleri, thus linking sequence diversity patterns and function in vivo (Hanikenne et al. 2013; Nouet et al. 2015).

HMA4 is also highly expressed in $N$. caerulescens as well as in $\mathrm{Zn}$ and $\mathrm{Cd}$ hyperaccumulator accessions of $S$. alfredii and $S$. plumbizincola, wherein it very likely plays similar roles to the $A$. halleri HMA4 (Bernard et al. 2004; Papoyan and Kochian 2004; van de Mortel et al. 2006; O' Lochlainn et al. 2011; Craciun et al. 2012; Zhang et al. 2016; Peng et al. 2017). Moreover, the gene coding for the ZIP transporter ZNT1 of $N$. caerulescens is highly expressed in cortex, endodermis, and pericycle root cells. When expressed in A. thaliana, it contributes to $\mathrm{Zn}$ and $\mathrm{Cd}$ tolerance and accumulation. The NcZNT1 gene therefore may be involved in $\mathrm{Zn}$ and $\mathrm{Cd}$ influx into cells responsible for xylem loading, providing metals for transport by HMA4 (Milner et al. 2014; Lin et al. 2016). The ortholog of ZNT1 in A. halleri, ZIP4, is also highly expressed and may contribute to a similar function (Talke et al. 2006). Note that NRAMP1 (Natural Resistance-Associated Macrophage Protein 1) may also play a similar role for Cd in N. caerulescens (Milner et al. 2014). Moreover, the vacuolar metal efflux transporters NRAMP3 and NRAMP4 are highly expressed in N. caerulescens and A. halleri roots, and were proposed to limit vacuolar storage and increase metal mobility (Weber et al. 2004; Oomen et al. 2009). NRAMP3 is also highly expressed in S. plumbizincola (Peng et al. 2017).

Once in the xylem sap, metals are transported to the shoot via the evapo-transpiration stream. Within this compartment, $\mathrm{Zn}$ is mainly bound to organic acids such as malate and citrate (Monsant et al. 2011; Lu et al. 2013; Cornu et al. 2015).

\subsubsection{Storage of zinc and cadmium in leaves}

It is suggested that HMA4 and ZIP transporters also play an important role in $\mathrm{Zn}$ unloading and distribution in shoot tissues (Krämer et al. 2007; Hanikenne and Nouet 2011). However, their exact contribution, as well as the contribution of metal ligands or other transporters, to these processes 
remains to be detailed. Zinc storage in vacuoles is most likely ensured by the MTP1 (Metal Tolerance Protein 1) protein in A. halleri; MTP1 is a vacuolar transporter implicated in Zn tolerance (Krämer 2005). The MTP1 gene is constitutively highly expressed in both root and shoot of $A$. halleri and is present in four to five copies that are located on three distinct linkage groups in the genome (Dräger et al. 2004; Talke et al. 2006; Willems et al. 2007; Shahzad et al. 2010; Fasani et al. 2017). The two most highly expressed copies each co-segregate with QTLs for Zn tolerance (Dräger et al. 2004; Willems et al. 2007; Shahzad et al. 2010).

MTP1 is also highly expressed in Noccaea (formerly Thlaspi) goesingensis, another $\mathrm{Zn}$ and $\mathrm{Ni}$ hyperaccumulator, in N. caerulescens, and in Zn-hyperaccumulating populations of S. alfredii (Milner and Kochian 2008; Gustin et al. 2009; Zhang et al. 2011). It likely plays a similar role in these species. No detailed information is currently available on the molecular mechanisms of Cd storage in $A$. halleri shoot vacuoles (Meyer and Verbruggen 2012). Indeed, MTP1 is not associated with high Cd tolerance or accumulation in A. halleri (Courbot et al. 2007; Willems et al. 2010). However, expression of MTP1-related proteins from the Ni hyperaccumulator $N$. goesingense were shown to confer Cd tolerance when expressed in yeast, suggesting an activity of $\mathrm{Cd}$ transport (Persans et al. 2001). The Heavy Metal ATPase HMA3, which localizes at the vacuole (Morel et al. 2009), may also contribute to this process in N. caerulescens (Ueno et al. 2011). Owing to RNAi lines, HMA3 was shown to be essential for Cd tolerance in shoots of S. plumbizincola (Liu et al. 2017).

Recent work suggests that specific mechanisms take place in the leaves of metal hyperaccumulators to protect the photosynthetic apparatus from excess of $\mathrm{Zn}$ and $\mathrm{Cd}$ (Bayçu et al. 2017; Szopiński et al. 2019). Indeed, HMA1 (Heavy Metal ATPase 1), encoding a chloroplastic metal transporter (Hanikenne and Baurain 2014), is highly expressed in shoots of S. plumbizincola (Zhao et al. 2019). HMA1 is required for $\mathrm{Cd}$ exclusion from the chloroplast: hmal mutant lines display increased $\mathrm{Cd}$ accumulation in chloroplasts, increased Cd sensitivity, and strongly altered photosystem II activity (Zhao et al. 2019). In A. halleri, mapping in a F2 progeny of an intraspecific cross between Italian metallicolous and nonmetallicolous individuals identified one major Zn tolerance QTL for photosynthetic yield. The NRAMP3 gene is associated with this QTL and was highly expressed in Zn-tolerant F2 plants (Karam et al. 2019). In A. thaliana, NRAMP3 and its paralog NRAMP4, contribute to excess $\mathrm{Zn}$ and Cd tolerance by mediating appropriate $\mathrm{Fe}$ and $\mathrm{Mn}$ supply to chloroplasts from vacuole stores, thus maintaining the photosynthetic function (Molins et al. 2013). NRAMP3 may play a similar role in $A$. halleri. 


\subsubsection{Additional candidate genes for zinc and cadmium accumulation and tolerance}

A few additional candidate genes for a role in $\mathrm{Zn}$ or $\mathrm{Cd}$ tolerance have been functionally characterized. In A. halleri, the PDF1.1 (Plant Defensin 1.1) protein was identified through a cDNA screen in yeast as being a contributor to $\mathrm{Zn}$ tolerance. It also confers $\mathrm{Zn}$ tolerance when ectopically overexpressed in A. thaliana and is more highly expressed in shoots of $A$. halleri compared to A. thaliana (Mirouze et al. 2006). PDFs were initially known as secreted antifungal proteins and are characterized by a cysteine-stabilized $\alpha$-helix $\beta$-sheet structure (De Coninck et al. 2013; van der Weerden and Anderson 2013). However, AhPDF1.1 localizes in intracellular compartments (Oomen et al. 2011). Family wide comparison of $A$. halleri and $A$. thaliana PDF1 genes revealed that the molecular function of the $A$. thaliana and A. halleri proteins in $\mathrm{Zn}$ tolerance and antifungal activity is conserved, and that functional differences in the two species may result from differential expression levels and regulation (Shahzad et al. 2013; Nguyen et al. 2014).

The fine-scale mapping of a QTL in $A$. halleri allowed the identification of CAX1 (cation/hydrogen exchanger 1) as a candidate gene for Cd tolerance (Courbot et al. 2007; Baliardini et al. 2015). CAX1 is localized in the vacuolar membrane and plays a key role in Ca homeostasis (Conn et al. 2011). CAXI is more expressed in roots of $A$. halleri compared to A. thaliana, and high expression of CAXI cosegregated with Cd tolerance in a back-cross 1 population of an A. halleri/A. lyrata cross. The CAXI QTL is conditional on Ca supply in the medium and is detected at low Ca supply only. Analyses of $A$. thaliana caxl mutant and $A$. halleri RNAi lines suggest that, at low Ca supply, $C A X 1$ is required to tolerate Cd-induced oxidative stress (Baliardini et al. 2015, 2016; Ahmadi et al. 2018). Recently, the high expression in shoots of multiple genes involved in the flavonoid pathway was linked to the capacity of a $A$. halleri population to tolerate and accumulate high $\mathrm{Cd}$ concentrations, suggesting that the capacity of accommodating Cd-induced oxidative damages is an important feature of $\mathrm{Cd}$ hyperaccumulation (Corso et al. 2018). Alternatively, flavonoids may bind $\mathrm{Cd}$ and be involved in $\mathrm{Cd}$ transport and sequestration (Kasprzak et al. 2015).

\subsection{Mechanisms of Nickel Hyperaccumulation}

Currently, more than $500 \mathrm{Ni}$ hyperaccumulator species have been identified worldwide. These species are scattered in more than 50 plant families, mostly dicotyledons (Krämer 2010; van der Ent et al. 2013; Cappa and Pilon-Smits 2014; Reeves et al. 2018). Despite this large diversity and the interest in understanding the underlying mechanisms as instrumental to improve Ni phytoextraction, only a limited number of studies have focused on the molecular mechanisms of Ni hyperaccumulation. Ni is 
an essential microelement for plants because it is required for urease activity (Polacco et al. 2013). Plants have, therefore, evolved mechanisms for the regulation of $\mathrm{Ni}$ homeostasis and $\mathrm{Ni}$ hyperaccumulation that likely derive from these mechanisms (Figure 8.3). In Arabidopsis thaliana, the regulation of $\mathrm{Ni}$ homeostasis is strongly linked to the regulation of Fe homeostasis, but some responses to $\mathrm{Ni}$ excess are independent of Ni-induced iron deficiency responses (Schaaf et al. 2006; Morrissey et al. 2009; Nishida et al. 2011; Lešková et al. 2019). Interestingly, in Ni hyperaccumulators of the Odontarrhena (Alyssum) genus, it was shown that Mn treatment reduces Ni accumulation, suggesting that in some species Ni hyperaccumulation may also use mechanisms primary involved in Mn homeostasis (Leigh Broadhurst et al. 2009; Ghaderian et al. 2015).

\subsubsection{Uptake of nickel}

Efficient uptake of $\mathrm{Ni}$ by the roots of hyperaccumulators requires divalent metal importers (e.g. ZIP, NRAMP) or transporters able to carry conjugated forms of Ni [e.g. Yellow Stripe-Like (YSL) family]. However, identity of the transporters involved in Ni uptake in hyperaccumulators is still not clearly established. In A. thaliana, the metal transporter IRT1 required for the uptake of Fe from soil was shown to be involved in Ni uptake (Vert et al. 2002; Nishida et al. 2011, 2012). Interestingly, the high expression of IRT1 orthologs in the roots of N. caerulescens and Senecio coronatus (Asteraceae) is correlated with the Ni hyperaccumulation capacity of tested accessions (Halimaa et al. 2014b; Meier et al. 2018). In addition, de novo sequencing of NcIRT1 in Monte Prinzera revealed sequence polymorphism in the large cytoplasmic loop of IRT1 that may play a role in transport specificity and/or regulation (Halimaa et al. 2014a). However, in other $\mathrm{Ni}$ hyperaccumulator accessions of $N$. caerulescens (i.e. Puy de Wolf and Bergenbach), we were unable to detect correlation between NcIRT1 expression and Ni hyperaccumulation (V.S. Garcia de la Torre, S. Merlot, unpublished data). These data suggest that metal transporters orthologous to IRT1 are likely involved in the efficient uptake of $\mathrm{Ni}$ in hyperaccumulator species. Other types of metal transporters may also participate in this important step. Indeed, several species of the ZIP and the NRAMP families have been linked to Ni transport or accumulation, but further studies will be required to support their implication in the efficient uptake of Ni in hyperaccumulators (Mizuno et al. 2005, 2007; Wei et al. 2009; Halimaa et al. 2014b; Meier et al. 2018).

\subsubsection{Root-to-shoot transfer of nickel}

The long-distance transport of $\mathrm{Ni}$ from roots to shoots requires several steps that involve metal transporters and chelators that are able to bind $\mathrm{Ni}$ in different $\mathrm{pH}$ environments. In hyperaccumulators, a large proportion of $\mathrm{Ni}$ is found as complexes with carboxylic acids including citrate and malate (for 
reviews see Callahan et al. 2006; Sarret et al. 2013). These organic acid complexes are stable in acidic compartments such as vacuoles and xylem. In particular, citrate-Ni was identified in the xylem sap of the Ni hyperaccumulator Odontarrhena serpyllifolia (Alves et al. 2011). Interestingly, an ortholog of the A. thaliana citrate transporter FRD3 of the Multidrug and Toxic compound Extrusion family (MATE) is more expressed in the hyperaccumulator $N$. caerulescens than in the related nonaccumulator A. thaliana (van de Mortel et al. 2006). AtFRD3 and its orthologue in rice, OsFRDL1, are involved in the translocation of Fe from root to shoot (Rogers and Guerinot 2002; Yokosho et al. 2009). Therefore, high expression of MATE transporters in the root pericycle of hyperaccumulators would increase the loading of xylem with citrate and therefore favour the translocation of citrate-Ni complex from root to shoot. However, no direct evidence supports the implication of MATE transporters in Ni hyperaccumulation. It is interesting to note that FRD3 is also highly expressed in $A$. halleri, which hyperaccumulates Zn. FRD3 transporters may therefore have a general function in metal hyperaccumulation, favouring long-distance transport of metal from root to shoot (Talke et al. 2006; Charlier et al. 2015).

NA also has a strong affinity for Ni over a wide range of $\mathrm{pH}$ and is proposed to bind Ni in more neutral compartments such as the cytoplasm or phloem (Callahan et al. 2006; Rellan-Alvarez et al. 2008; Alvarez-Fernandez et al. 2014). Accordingly, over-expression of NA synthase in transgenic $A$. thaliana increases Ni tolerance but is not sufficient to improve Ni accumulation (Pianelli et al. 2005). A NA-Ni complex was identified in the xylem sap of $N$. caerulescens (Mari et al. 2006), in the latex of the Ni hyperaccumulator Pycnandra acuminata (Schaumlöffel et al. 2003), and in extracts of several hyperaccumulator species (Callahan et al. 2012). Transporters of the YSL family have been shown to transport NA-metal complexes (Curie et al. 2009; Conte and Walker 2012). Several genes coding for YSL transporters are more expressed in the hyperaccumulator $N$. caerulescens than in the related nonaccumulator A. thaliana (Gendre et al. 2007). Among these transporters, NcYSL3 that is able to transport the NA-Ni complex, is expressed in the vasculature of roots and leaves, suggesting a role in long-distance Ni transport.

Finally, the amino acid histidine (His), whose concentration in some hyperaccumulators of the Odontarrhena and Noccaea genera correlates with Ni accumulation, is proposed to play a role in the radial transport of Ni (Krämer et al. 1996; Richau et al. 2009). His has a strong affinity for Ni and an His-Ni complex has been identified in samples from Odontarrhena and Noccaea hyperaccumulators (Krämer et al. 1996; Persans et al. 1999; Callahan et al. 2006; McNear et al. 2010). Genes acting at different steps of His biosynthesis have been shown to be more expressed in Ni hyperaccumulators 
from several plant families than in related non-accumulator species (Ingle et al. 2005; Garcia de la Torre et al. 2018). The over-expression of the first enzyme of the His biosynthetic pathway, ATPphosphoribosyltransferase, in Arabidopsis thaliana increases $\mathrm{Ni}$ tolerance but not $\mathrm{Ni}$ content, suggesting that other mechanisms are necessary for accumulation of this metal (Wycisk et al. 2004; Ingle et al. 2005).

Treatment of plants with His-Ni increases xylem loading and inhibits Ni uptake from root vacuoles (Richau et al. 2009). It was therefore proposed that the high concentration of His in roots of $\mathrm{Ni}$ hyperaccumulators prevents vacuolar storage, favouring radial transport and xylem loading (Kerkeb and Krämer 2003; Richau et al. 2009). However, the mechanism responsible for the inhibition of Ni vacuolar sequestration by His is still unknown. In addition, it is currently not known if this strategy is widely conserved in Ni hyperaccumulators and if this is relevant in the natural environment (e.g. serpentine soil), where nitrogen is limiting (Alves et al. 2011; Centofanti et al. 2013).

\subsubsection{Storage of nickel in leaves}

In most of the hyperaccumulators that have been studied to date, $\mathrm{Ni}$ is stored in the vacuole of leaf epidermal cells (for review Sarret et al. 2013). However, the cell wall of leaf cells can also represent a reservoir for nickel (Krämer et al. 2000; van der Ent et al. 2019). Several lines of evidence indicate that Ferroportin (FPN)/Iron Regulated (IREG) transporters play an essential role in the sequestration of $\mathrm{Ni}$ in vacuoles. In A. thaliana, AtIREG2 is expressed in roots in response to Fe starvation and the AtIREG2 protein localizes on the vacuole. The analysis of the ireg2 mutant indicated that AtIREG2 is involved in the storage of $\mathrm{Ni}$ excess and $\mathrm{Co}$ in the vacuole of root cells (Schaaf et al. 2006; Morrissey et al. 2009). In addition, a second closely related IREG transporter in A. thaliana, named FPN1/IREG1, is localized at the plasma membrane and is proposed to play a role in the loading of metals in the xylem in roots (Morrissey et al. 2009). Interestingly, the ortholog of AtIREG2 in A. lyrata is genetically linked to serpentine adaptation (Turner et al. 2010). Recent comparative transcriptomic analysis using RNASeq technology revealed that a high expression of genes coding for orthologs of AtIREGs in both roots and shoots is correlated with the Ni hyperaccumulation trait in several plant families (Halimaa et al. 2014b; Meier et al. 2018; Garcia de la Torre et al. 2018). For example, the PgIREG1 transporter from the Ni hyperaccumulator Psychotria gabriellae (Rubiaceae) localizes in the vacuolar membrane and is able to transport Ni when expressed in yeast. Therefore, PgIREG1 seems to be a functional homolog of AtIREG2. Interestingly, PgIREG1 is more expressed in leaves of P. gabriellae than in the closely related non-accumulator $P$. semperflorens when both species are growing on their natural environment within ultramafic soil (Merlot et al. 2014). The overexpression of AtIREG2 and PgIREG1 in transgenic 
Arabidopsis plants significantly increases $\mathrm{Ni}$ tolerance but does not increase Ni accumulation, indicating that the high expression of these transporters is insufficient to trigger Ni hyperaccumulation (Schaaf et al. 2006; Merlot et al. 2014). Together, these results suggest that FPN/ IREG transporters play a conserved role in the sequestration of $\mathrm{Ni}$ in the vacuoles of hyperaccumulators. We cannot exclude the possibility that FPN/ IREG transporters located at the plasma membrane might play a role in the radial transport of $\mathrm{Ni}$ and the exclusion of $\mathrm{Ni}$ to the cell wall of epidermal cells. Other families of divalent metal exporters such as MTP transporters could mediate the transport of Ni in vacuoles but their role in hyperaccumulation needs to be further supported (Persans et al. 2001).

\subsection{Hyperaccumulation of Other Trace Elements}

Species that are able to hyperaccumulate Mn have been identified in more than 20 genera mostly in the Myrtaceae (e.g. Gossia) and Proteaceae (e.g. Virotia) families (Fernando et al. 2013; Losfeld et al. 2015; Reeves et al. 2018). Similar to other metals, Mn hyperaccumulation likely evolved from basic mechanisms involved in Mn homeostasis, although these mechanisms are poorly investigated in $\mathrm{Mn}$ hyperaccumulators (Pittman 2005; Fernando et al. 2013; Socha and Guerinot 2014; Shao et al. 2017; Li et al. 2019). In hyperaccumulators, Mn was found to accumulate in the vacuole of nonphotosynthetic epidermal cells, but also more surprisingly in photosynthetic palisade mesophyll cells in the hyperaccumulator Virotia neurophylla (Fernando et al. 2012). These differences in the localization of Mn suggest that some mechanisms involved in Mn accumulation and detoxification might be divergent among hyperaccumulators. The high concentration of $\mathrm{Mn}$ measured in the leaves of several species is proposed to be the consequence of their strategy to acquire P from soil. For example, Proteaceae species excrete carboxylates in their rhizosphere that not only solubilize P but also micronutrients including Mn (Lambers et al. 2015). Several metal transporter families, such as NRAMP, ZIP, YSL and MTP have been shown to transport Mn in plants but their role in hyperaccumulation is not clearly established (Fernando et al. 2013; Socha and Guerinot 2014; Shao et al. 2017; Li et al. 2019). Most NRAMP transporters are able to transport Mn in the cytoplasm either from the exterior of the cell or from the vacuole, and therefore could participate in several steps of $\mathrm{Mn}$ hyperaccumulation. In particular, the NRAMP1 transporter from A. thaliana was shown to be the main transporter involved in Mn uptake in roots (Cailliatte et al. 2010). The ShMTP8 transporter (previously known as ShMTP1) was isolated from the Mn-tolerant species Stylosanthes hamata (Fabaceae). This MTP transporter confers Mn resistance when expressed in yeast and was proposed to mediate accumulation of $\mathrm{Mn}$ in the vacuole of plant cells (Delhaize et al. 2003). Further molecular studies on Mn hyperaccumulators will be required in order to identify the mechanisms that are key for $\mathrm{Mn}$ hyperaccumulation. 
In addition to the above-mentioned metals, mechanisms involved in the hyperaccumulation of the metalloid element $\mathrm{Se}$ in plants are extensively studied because of their relevance to improve $\mathrm{Se}$ phytoremediation and biofortification. We only briefly address Se hyperaccumulation here and refer interested readers to recent thorough reviews of our current knowledge on Se homeostasis and hyperaccumulation (Barillas et al. 2011; White 2016; Schiavon and Pilon-Smits 2017; Lima et al. 2018; Reynolds and Pilon-Smits 2018). Selenium hyperaccumulation has been described in more than 40 taxa scattered among seven families (Reeves et al. 2018). More than half of Se hyperaccumulators have been described in the genus Astragalus (Fabaceae), but other well-described Se hyperaccumulators have been found in the genera Stanleya (Brassicaceae), Oonopsis and Xylorhiza (Asteraceae). The distribution of Se hyperaccumulators among plant families suggests that Se hyperaccumulation likely evolved independently at least six times (Cappa and Pilon-Smits 2014). Selenium is available to plants mostly as selenate $\left(\mathrm{SeO}_{4}{ }^{2-}\right)$, a structural homologue of sulfate, or as selenite $\left(\mathrm{SeO}_{3}{ }^{2-}\right)$, depending on the nature of the soil (Elrashidi et al. 1987). In cultivated soils, selenate uptake by root cells is catalyzed by high-affinity sulfate transporters of the SULTR family (Shibagaki et al. 2002; El Kassis et al. 2007; Barberon et al. 2008). A recent comparative RNA-Seq study revealed that several members of the SULTR family are more expressed in the hyperaccumulator Stanleya pinnata than in the non-accumulator S. elata (Wang et al. 2018), thus confirming and extending previous results observed in the Astragalus genus (Freeman et al. 2010; Cabannes et al. 2011; Schiavon et al. 2015). The high and constitutive expression of these transporters are proposed to significantly increase $\mathrm{SeO}_{4}{ }^{2-}$ uptake and translocation to aerial parts of plants. The hyperaccumulation of Se is also linked to the capacity to preferentially take up selenate over sulfate. Sequence analysis of SULTR1 transporters from Astragalus identified a Gly to Ala polymorphism linked to the hyperaccumulation trait (Cabannes et al. 2011). However, it is not yet known if this difference explains the preferential uptake of selenate over sulfate. In rice growing in anerobic soils (e.g. paddy fields), selenite forms are transported in root cells by the phosphate transporters OsPT2 (Zhang et al. 2014) and by aquaporins (Zhao et al. 2010). Long-distance transport of selenate to the shoot is also proposed to be mediated by SULTR transporters (Takahashi et al. 2000). In shoots, the main fraction of selenate is metabolized into organo-selenium compounds (SeCys and SeMet) in chloroplast (Barillas et al. 2011; White 2016; $\mathrm{Zhu}$ et al. 2009). In hyperaccumulator species, genes involved in the synthesis of organo-selenium compounds and in the methylation of SeCys to produce the non-toxic form MeSeCys were shown to be constitutively more expressed than in non-accumulator species, supporting the metabolism of Se as also key for its hyperaccumulation (Pickering et al. 2003; Freeman et al. 2010; Schiavon et al. 2015; Wang et al. 2018). 


\subsection{Perspectives and Conclusions}

\subsubsection{Interaction of hyperaccumulators with biotic environment}

The so-called 'elemental defense' hypothesis proposes that metal hyperaccumulation provides defense against pathogens and/or herbivores by direct toxicity (Boyd and Martens 1992; Hörger et al. 2013; Cabot et al. 2019). Indeed, it has been shown that $\mathrm{Ni}$ and $\mathrm{Zn}$ accumulation can protect different Brassicaceae species from bacterial and fungal infection (Boyd et al. 1994; Ghaderian et al. 2000; Fones et al. 2010). However, it is also well documented that in environmental conditions, specific populations of bacteria are associated with the root system of metal hyperaccumulators (Aboudrar et al. 2012; Cabello-Conejo et al. 2014; Lucisine et al. 2014; Muehe et al. 2015). Endophytic bacteria have also been identified in shoots and roots of metal hyperaccumulators (Idris et al. 2004; Mengoni et al. 2009a). However, since the majority of these bacteria are not cultivable, current studies mostly describe endophytic populations using metagenomics approaches (Luo et al. 2011; Sessitsch et al. 2012; Chen et al. 2014; Visioli et al. 2014; Cao et al. 2020; Wang et al. 2020). Interestingly, it was shown that the inoculation of $N$. caerulescens and O. serpyllifolia s.l. with cultivable endophytic bacteria increases Ni translocation to shoots (Ma et al. 2011b; Visioli et al. 2015), and the inoculation of Sedum alfredii with Pseudomonas fluorescens enhances lateral root growth, photosynthesis, carbon fixation, and $\mathrm{Cd}$ accumulation in shoots (Wu et al. 2020a, b).

Little is known about the interactions between metal hyperaccumulators and associated bacteria. Metal hyperaccumulators represent an extreme niche for metal-tolerant bacteria (Mengoni et al. 2009b). On the other hand, such bacteria can improve plant growth and confer protection against abiotic stress by the production of hormones (auxins, cytokinins, etc.), or protect the host plant against other pathogens by the production of antagonistic substances or by competition for space and nutrients (Ma et al. 2011b; Reinhold-Hurek and Hurek 2011; Wu et al. 2020a). Metal-tolerant bacteria can also produce organic acids and metal chelators that can favour metal solubility, transport, and tolerance (Idris et al. 2006; Ma et al. 2011a; Visioli et al. 2015). These observations suggest intimate interactions between hyperaccumulators and associated bacteria; however, the mechanisms and genes involved in these interactions are mostly unknown. The development of next-generation sequencing technologies for metagenomic and meta-transcriptomic (or dual-transcriptomic) analyses, combined with functional and signalling networks, will uncover those genes expressed by plants and associated bacteria involved in their symbiotic interaction (Camilios-Neto et al. 2014; Pankievicz et al. 2016). Understanding these mechanisms will be instrumental for improving metal phytoextraction and plant biofortification, or for 
producing secondary metabolites such as metal chelators of bacterial origin that can be used in metalbased therapies (Franz 2013).

\subsubsection{Evolution of hyperaccumulation mechanisms}

After this brief review of our current knowledge of the molecular mechanisms of $\mathrm{Zn}$ and $\mathrm{Cd}$ or $\mathrm{Ni}$ hyperaccumulation, it is apparent that several candidate genes involved in these processes are involved in the control of metal homeostasis in non-accumulator plants. These genes display an enhanced function in hyperaccumulators, through gene copy number amplification and/or altered regulation, which profoundly modifies the metal flux in the plants towards accumulation in shoots. Many examples were also presented on the high level of convergent evolution between $A$. halleri, $N$. caerulescens, and $S$. alfredii. This convergent evolution likely reflects (and sheds light on) the functional constraints of the metal homeostasis network (Krämer et al. 2007; Verbruggen et al. 2009; Krämer 2010; Hanikenne and Nouet 2011; Preite et al. 2019). The key function of HMA4 in several hyperaccumulator species represents a potent example of this convergent evolution for $\mathrm{Zn}$ and $\mathrm{Cd}$ accumulation (Hanikenne et al. 2008; O' Lochlainn et al. 2011; Craciun et al. 2012). The high expression of FPN/IREG transporters in leaves of Ni hyperaccumulators from different families represents another example of convergence for the evolution of Ni hyperaccumulation (Halimaa et al. 2014b; Meier et al. 2018; Garcia de la Torre et al. 2018). Recently, polymorphism and high expression of IRT1 orthologs was found to be directly associated with both $\mathrm{Cd}$ and Ni hyperaccumulation in distant plant species (Halimaa et al. 2014a; Halimaa et al. 2014b; Corso et al. 2018; Meier et al. 2018; Schvartzman et al. 2018). IRT1 represents the major high-affinity Fe uptake system in Dicotyledons, but has a low specificity for divalent metal ions in contrast to the more specific Fe-chelates system used by Monocotyledons (Korshunova et al. 1999; Vert et al. 2002; Nishida et al. 2011; Thomine and Vert 2013; Kobayashi et al. 2019). These results therefore support the hypothesis that the different pathways used for Fe uptake explain why the majority of metal hyperaccumulators have been identified in Dicotyledons.

Metal hyperaccumulation and associated (hyper)tolerance are complex traits that required the finetuning of multiple mechanisms during the course of plant evolution. Only a small number of largeeffect QTL have been detected to date, suggesting that additional modifier genes involved in metal tolerance and hyperaccumulation remain to be detected. Moreover, if several key players have now been identified, how the tolerance and hyperaccumulation traits evolved remains an open 'chicken and egg' question. Hence, Bayesian inference suggested that speciation between A. halleri and A. lyrata closely coincided with HMA4 duplication (Roux et al. 2011). Complex signature of selection detected 
at the HMA4 locus of A. halleri further supports the key role of the gene in the evolution of the hyperaccumulation trait (Hanikenne et al. 2013). Recent adaptations to anthropogenic metal-polluted sites possibly occurred independently within distinct phylogeographic units of the A. halleri European distribution (Pauwels et al. 2012). Hypertolerance of metallicolous populations thus potentially evolved using a variety of genetic mechanisms (Meyer et al. 2009, 2010; Pauwels et al. 2012; BabstKostecka et al. 2018). Moreover, the study by Meyer et al. (Meyer et al. 2016) suggests that, if HMA4 contributes to $\mathrm{Zn}$ tolerance in both metallicolous and non-metallicolous populations of $\mathrm{A}$. halleri (Hanikenne et al. 2013), the function of MTP1 in Zn tolerance may have evolved later in metallicolous populations that have colonized polluted soils recently. Indeed, the co-segregation of MTP1 with $\mathrm{Zn}$ tolerance is only observed in a back-cross 1 population of a cross between a French metallicolous individual (i.e. living on metal-polluted soil) of A. halleri and A. lyrata and is lost when a nonmetallicolous Slovakian (i.e. living on non-polluted soil) A. halleri individual is used as parent (Meyer et al. 2016). In contrast, the co-segregation of HMA4 with $\mathrm{Zn}$ tolerance is independent of the edaphic origin of the A. halleri populations used in the analysis (Willems et al. 2007; Meyer et al. 2016). This result partially contradicts the hypothesis that MTP1 is required for metal detoxification accommodating the high HMA4-dependent metal flux into A. halleri shoots, which was proposed based on the observation that expression of AhHMA4 in non-accumulator plants resulted in increased sensitivity to excess Zn (Hanikenne et al. 2008; Barabasz et al. 2010). However, MTPl is highly expressed in four metalicollous populations from distinct genetic units (Dräger et al. 2004; Talke et al. 2006; Schvartzman et al. 2018), which either suggests convergent evolution in several metalicollous populations with parallel acquisition of high expression of multiple MTPl copies or that the lack of MTP1 may be a specific feature of the non-metallicolous Slovakian population previously described (Meyer et al. 2016).

More recently, the QTL (Karam et al. 2019) and transcriptomic (Halimaa et al. 2014b; Milner et al. 2014; Corso et al. 2018; Schvartzman et al. 2018) approaches used so far to compare hyperaccumulator and non-accumulator related species were extended to comparisons of contrasting populations within species, taking advantage of important intraspecific variation of hypertolerance and hyperaccumulation traits observed among populations of distinct geographic regions or established on distinct edaphic types (Escarré et al. 2000; Pauwels et al. 2006; Gonneau et al. 2014; Stein et al. 2017). Exploiting this natural variation, application of Genome-Wide Association Studies (GWAS) in large cohorts of wild plants (or accessions) of a species will further allow identifying novel alleles linked to the variation of a phenotype. As complementary techniques, Transcriptome-Wide Association Studies (TWAS) and expression Quantitative Trait Loci (eQTL) could also be used to identify regulatory 
sequence variants and to prioritize candidate genes at the identified loci. Furthermore, these techniques not yet applied to address metal tolerance and hyperaccumulation in plants will facilitate the modelling of functional and/or regulatory networks underlying the complex traits.

Recent studies have used omics approaches to characterize genome- or transcriptome-wide genetic variation within species and to uncover mechanisms of evolution of metal hyperaccumulation (Yang et al. 2017; Paape et al. 2018; Sailer et al. 2018; Halimaa et al. 2019; Preite et al. 2019; Honjo and Kudoh 2019). These studies started to reveal the pattern of polymorphisms in genomes and to shed light on how selection acts on those genomes. This variation has been exploited to select or breed lines of $N$. caerulescens with increased tolerance and/or accumulation (Nowak et al. 2018; Sterckeman et al. 2019).

The study of metal hyperaccumulation in distant plant families combined with the comparison of distinct accessions with contrasting accumulation capabilities within a species will likely shed light on the evolution of the hyperaccumulation and hypertolerance traits. This approach may indeed reveal the commonalities and differences in mechanisms underlying these traits, highlighting evolutionary divergence and convergence. It may also reveal evolutionary 'intermediates’ (i.e. genotypes that don’t display the full extent of hyperaccumulation or tolerance), which may allow ordering the evolutionary events that took place during the adaptation of the metal homeostasis network.

\subsubsection{How can phytoextraction technologies benefit from molecular knowledge?}

To date, most of our knowledge on metal hyperaccumulation arises from studies of a few model hyperaccumulator species (i.e. A. halleri and N. caerulescens) of the Brassicaceae family. In the future, it will be necessary to pursue molecular studies and improve genetic manipulation of these species in order to identify and demonstrate the role of key mechanisms involved in metal hyperaccumulation. Furthermore, these species have a low biomass and a relatively restricted distribution worldwide. Therefore, one of the coming challenges for the development of agromining/phytoextraction will be to transfer knowledge of the mechanisms involved in metal hyperaccumulation to species having a high potential for phytoextraction. As mentioned above, the development of Next Generation Sequencing technologies opens the possibility for studying 'non-model' species at the genomic and transcriptomic levels.

As for other crop plants, this molecular knowledge will be instrumental to develop markers for the selection of genotypes with the best potential for metal phytoextraction. The level of expression of key 
genes involved in metal hyperaccumulation can be used to predict metal accumulation capacities. These marker genes can also be used to study the interaction between metal accumulation and agricultural practices (e.g. fertilization), and for improving biomass production while maintaining efficient metal accumulation.

Finally, genome-editing technologies such as CRISPR-CAS9 are currently being implemented in plants to specifically modify the sequence of target genes (Chen et al. 2019). This technology offers several advantages compared to traditional transformation technologies used to produce Genetically Modified Organisms (GMO), and therefore could be better accepted by civil society and political stakeholders to engineer crop plants for metal phytoextraction. Recently, this technology was used to inactivate the $S d H M A 1$ gene coding for a chloroplast $\mathrm{Cd}$ exporter in the hyperaccumulator Sedum plumbizincicola (Zhao et al. 2019). Further development of this technology may allow for specifically introducing point mutations in the sequence of genes involved in metal accumulation to increase their activity, improve their specificity, or modify their selectivity towards metals of interest (Rogers et al. 2000; Menguer et al. 2013; Pottier et al. 2015).

\section{Acknowledgements}

We thank colleagues in our laboratories for critical reading of the manuscript. The research of SM and VSGT was supported by the French National Research Agency (ANR-13-ADAP-0004) and by CNRS (Defi Enviromics and Defi X-Life). Funding to $\mathrm{MH}$ is from the 'Fonds de la Recherche ScientifiqueFNRS' (PDR-T.0206.13, MIS-F.4511.16, CDR J.0009.17, PDR-T0120.18) and the University of Liège (SFRD-12/03, ARC GreenMagic). MH is a Senior Research Associate of the FNRS.

\section{References}

Aboudrar W, Schwartz C, Morel JL, Boularbah A (2012) Effect of nickel-resistant rhizosphere bacteria on the uptake of nickel by the hyperaccumulator Noccaea caerulescens under controlled conditions. J Soils Sediment 13:501-507

Ahmadi H, Corso M, Weber M et al. (2018) CAX1 suppresses Cd-induced generation of reactive oxygen species in Arabidopsis halleri. Plant Cell Environ 41:2435-2448

Alvarez-Fernandez A, Diaz-Benito P, Abadia A et al. (2014) Metal species involved in long distance metal transport in plants. Front Plant Sci 5:105 
Alves S, Nabais C, Simoes Goncalves M de L, Correia Dos Santos MM (2011) Nickel speciation in the xylem sap of the hyperaccumulator Alyssum serpyllifolium ssp. lusitanicum growing on serpentine soils of northeast Portugal. J Plant Physiol 168:1715-1722

Assunção AGL, Bookum WM, Nelissen HJM et al. (2003) Differential metal-specific tolerance and accumulation patterns among Thlaspi caerulescens populations originating from different soil types. New Phytol 159:411-419

Assunção AGL, Herrero E, Lin YF et al. (2010) Arabidopsis thaliana transcription factors bZIP19 and bZIP23 regulate the adaptation to zinc deficiency. Proc Natl Acad Sci USA 107:10296-10301

Babst-Kostecka A, Schat H, Saumitou-Laprade P et al. (2018) Evolutionary dynamics of quantitative variation in an adaptive trait at the regional scale: The case of zinc hyperaccumulation in Arabidopsis halleri. Mol Ecol 27:3257-3273

Baliardini C, Corso M, Verbruggen N (2016) Transcriptomic analysis supports the role of CATION EXCHANGER 1 in cellular homeostasis and oxidative stress limitation during cadmium stress. Plant Signal Behav 11:e1183861

Baliardini C, Meyer C-L, Salis P et al. (2015) CATION EXCHANGER1 cosegregates with cadmium tolerance in the metal hyperaccumulator Arabidopsis halleri and plays a role in limiting oxidative stress in Arabidopsis spp. Plant Physiol 169:549-559

Barabasz A, Krämer U, Hanikenne M et al. (2010) Metal accumulation in tobacco expressing Arabidopsis halleri metal hyperaccumulation gene depends on external supply. J Exp Bot 61:30573067

Barberon M, Berthomieu P, Clairotte M et al. (2008) Unequal functional redundancy between the two Arabidopsis thaliana high-affinity sulphate transporters SULTR1;1 and SULTR1;2. New Phytol 180:608-619

Barberon M, Zelazny E, Robert S et al. (2011) Monoubiquitin-dependent endocytosis of the IronRegulated Transporter 1 (IRT1) transporter controls iron uptake in plants. Proc Natl Acad Sci USA 108:E450-E458 
Barillas JR V, Quinn CF, Pilon-Smits EAH (2011) Selenium accumulation in plantsphytotechnological applications and ecological implications. Int J Phytoremediation 13:166-178

Bayçu G, Gevrek-Kürüm N, Moustaka J et al. (2017) Cadmium-zinc accumulation and photosystem II responses of Noccaea caerulescens to Cd and Zn exposure. Environ Sci Pollut Res 24:2840-2850

Becher M, Talke IN, Krall L, Krämer U (2004) Cross-species microarray transcript profiling reveals high constitutive expression of metal homeostasis genes in shoots of the zinc hyperaccumulator Arabidopsis halleri. Plant J 37:251-268

Bernard C, Roosens N, Czernic P et al. (2004) A novel CPx-ATPase from the cadmium hyperaccumulator Thlaspi caerulescens. FEBS Lett 569:140-148

Bert V, Bonnin I, Saumitou-Laprade P et al. (2002) Do Arabidopsis halleri from non metallicolous populations accumulate zinc and cadmium more effectively than those from metallicolous populations? New Phytol 155:47-57

Bert V, Macnair MR, De Laguérie P et al. (2000) Zinc tolerance and accumualtion in metallicolous and non metallicolous populations of Arabidopsis halleri (Brassicaceae). New Phytol 146:225-233

Besnard G, Basic N, Christin PA et al. (2009) Thlaspi caerulescens (Brassicaceae) population genetics in western Switzerland: is the genetic structure affected by natural variation of soil heavy metal concentrations? New Phytol 181:974-984

Boyd R, Martens S (1992) In: The Vegetation of Ultramafic (Serpentine) Soils. AJM Baker, J Proctor and RD Reeves (eds). Andover, Hampshire: Intercept Limited, UK, pp 279-289

Boyd RS, Shaw JJ, Martens SN (1994) Nickel hyperaccumulation defends Streptanthus polygaloides (Brassicaceae) against pathogens. Am J Bot 81:294-300

Burkhead JL, Reynolds KA, Abdel-Ghany SE et al. (2009) Copper homeostasis. New Phytol $182: 799-816$ 
Cabannes E, Buchner P, Broadley MR, Hawkesford MJ (2011) A comparison of sulfate and selenium accumulation in relation to the expression of sulfate transporter genes in Astragalus species. Plant Physiol 157:2227-2239

Cabello-Conejo MI, Becerra-Castro C, Prieto-Fernández A et al. (2014) Rhizobacterial inoculants can improve nickel phytoextraction by the hyperaccumulator Alyssum pintodasilvae. Plant Soil $379: 35-50$

Cabot C, Martos S, Llugany M et al. (2019) A role for zinc in plant defense against pathogens and herbivores. Front. Plant Sci. 10:1171

Cailliatte R, Schikora A, Briat JF et al. (2010) High-affinity manganese uptake by the metal transporter NRAMP1 is essential for Arabidopsis growth in low manganese conditions. Plant Cell 22:904-917

Callahan DL, Baker AJM, Kolev SD, Wedd AG (2006) Metal ion ligands in hyperaccumulating plants. J Biol Inorg Chem 11:2-12

Callahan DL, Hare DJ, Bishop DP et al. (2016) Elemental imaging of leaves from the metal hyperaccumulating plant Noccaea caerulescens shows different spatial distribution of $\mathrm{Ni}, \mathrm{Zn}$ and $\mathrm{Cd}$. RSC Adv 6:2337-2344

Callahan DL, Kolev SD, O’Hair RAJ et al. (2007) Relationships of nicotianamine and other amino acids with nickel, zinc and iron in Thlaspi hyperaccumulators. New Phytol 176:836-848

Callahan DL, Roessner U, Dumontet V, de Livera AM, Doronila A, Baker AJM, Kolev S (2012) Elemental and metabolite profiling of nickel hyperaccumulators from New Caledonia. Phytochemistry 81:80-89

Camilios-Neto D, Bonato P, Wassem R et al. (2014) Dual RNA-seq transcriptional analysis of wheat roots colonized by Azospirillum brasilense reveals up-regulation of nutrient acquisition and cell cycle genes. BMC Genomics 15:378 
Cao D, Zhang H, Wang Y, Zheng L (2014) Accumulation and distribution characteristics of zinc and cadmium in the hyperaccumulator plant Sedum plumbizincicola. Bull Env Contam Toxicol 93:171176

Cao X, Luo J, Wang X et al. (2020) Responses of soil bacterial community and Cd phytoextraction to a Sedum alfredii - oilseed rape (Brassica napus L. and Brassica juncea L.) intercropping system. Sci Total Environ 723:138152

Cappa JJ, Pilon-Smits EAH (2014) Evolutionary aspects of elemental hyperaccumulation. Planta 239:267-275

Centofanti T, Sayers Z, Cabello-Conejo MI et al. (2013) Xylem exudate composition and root-toshoot nickel translocation in Alyssum species. Plant Soil 373:59-75

Charlier JB, Polese C, Nouet C et al. (2015) Zinc triggers a complex transcriptional and posttranscriptional regulation of the metal homeostasis gene FRD3 in Arabidopsis relatives. J Exp Bot $66: 3865-3878$

Chen K, Wang Y, Zhang R et al. (2019) CRISPR/Cas genome editing and precision plant breeding in agriculture. Annu Rev Plant Biol 70:667-697

Chen L, Luo S, Chen J et al. (2014) A comparative analysis of endophytic bacterial communities associated with hyperaccumulators growing in mine soils. Env Sci Pollut Res Int 21:7538-7547

Chiang HC, Lo JC, Yeh KC (2006) Genes associated with heavy metal tolerance and accumulation in $\mathrm{Zn} / \mathrm{Cd}$ hyperaccumulator Arabidopsis halleri: a genomic survey with cDNA microarray. Env Sci Technol 40:6792-6798

Claus J, Bohmann A, Chavarría-Krauser A (2013) Zinc uptake and radial transport in roots of Arabidopsis thaliana: a modelling approach to understand accumulation. Ann Bot 112:369-380

Clauss MJ, Koch MA (2006) Poorly known relatives of Arabidopsis thaliana. Trends Plant Sci 11:449-459 
Clemens S (2019) Metal ligands in micronutrient acquisition and homeostasis. Plant Cell Environ 42:2902-2912

Clemens S, Deinlein U, Ahmadi H et al. (2013) Nicotianamine is a major player in plant Zn homeostasis. Biometals 26:623-632

Clemens S, Palmgren MG, Krämer U (2002) A long way ahead: understanding and engineering plant metal accumulation. Trends Plant Sci 7:309-15

Conn SJ, Gilliham M, Athman A et al. (2011) Cell-specific vacuolar calcium storage mediated by CAX1 regulates apoplastic calcium concentration, gas exchange, and plant productivity in Arabidopsis. Plant Cell 23:240-257

Conte SS, Walker EL (2012) Genetic and biochemical approaches for studying the Yellow StripeLike transporter family in plants. Curr Top Membr 69:295-322

Cornu J, Deinlein U, Horeth S et al. (2015) Contrasting effects of nicotianamine synthase knockdown on zinc and nickel tolerance and accumulation in the zinc/cadmium hyperaccumulator Arabidopsis halleri. New Phytol 206:738-750

Corso M, Schvartzman MS, Guzzo F et al. (2018) Contrasting cadmium resistance strategies in two metallicolous populations of Arabidopsis halleri. New Phytol 218:283-297

Cosio C, DeSantis L, Frey B et al. (2005) Distribution of cadmium in leaves of Thlaspi caerulescens. J Exp Bot 56:765-775

Courbot M, Willems G, Motte P et al. (2007) A major QTL for Cd tolerance in Arabidopsis halleri co-localizes with HMA4, a gene encoding a Heavy Metal ATPase. Plant Physiol 144:1052-1065

Craciun AR, Courbot M, Bourgis F et al. (2006) Comparative cDNA-AFLP analysis of Cd-tolerant and -sensitive genotypes derived from crosses between the $\mathrm{Cd}$ hyperaccumulator Arabidopsis halleri and Arabidopsis lyrata ssp. petraea. J Exp Bot 57:2967-2983 
Craciun AR, Meyer C-L, Chen J et al. (2012) Variation in HMA4 gene copy number and expression among Noccaea caerulescens populations presenting different levels of $\mathrm{Cd}$ tolerance and accumulation. J Exp Bot 63:4179-4189

Curie C, Cassin G, Couch D et al. (2009) Metal movement within the plant: contribution of nicotianamine and Yellow Stripe 1-Like transporters. Ann Bot 103:1-11

De Coninck B, Cammue BPA, Thevissen K (2013) Modes of antifungal action and in planta functions of plant defensins and defensin-like peptides. Fungal Biol Rev 26:109-120

Deinlein U, Weber M, Schmidt H et al. (2012) Elevated nicotianamine levels in Arabidopsis halleri roots play a key role in zinc hyperaccumulation. Plant Cell 24:708-723

Delhaize E, Kataoka T, Hebb DM et al. (2003) Genes encoding proteins of the cation diffusion facilitator family that confer manganese tolerance. Plant Cell 15:1131-1142

Deng DM, Shu WS, Zhang J et al. (2007) Zinc and cadmium accumulation and tolerance in populations of Sedum alfredii. Environ Pollut 147:381-386

Deniau AX, Pieper B, Ten Bookum WM et al. (2006) QTL analysis of cadmium and zinc accumulation in the heavy metal hyperaccumulator Thlaspi caerulescens. Theor Appl Genet 113:907-920

Dräger DB, Desbrosses-Fonrouge AG, Krach C et al. (2004) Two genes encoding Arabidopsis halleri MTP1 metal transport proteins co-segregate with zinc tolerance and account for high MTP1 transcript levels. Plant J 39:425-439

El Kassis E, Cathala N, Rouached H et al. (2007) Characterization of a selenate-resistant Arabidopsis mutant. Root growth as a potential target for selenate toxicity. Plant Physiol 143:1231-1241

Elrashidi MA, Adriano DC, Workman SM, Lindsay WL (1987) Chemical-equilibria of selenium in soils - a theoretical development. Soil Sci 144:141-152 
Escarré J, Lefebvre C, Frérot H et al. (2013) Metal concentration and metal mass of metallicolous, non metallicolous and serpentine Noccaea caerulescens populations, cultivated in different growth media. Plant Soil 370:197-221

Escarré J, Lefèbvre C, Gruber W et al. (2000) Zinc and cadmium hyperaccumulation by Thlaspi caerulescens from metalliferous and nonmetalliferous sites in the Mediterranean area: implications for phytoremediation. New Phytol 145:429-437

Fasani E, DalCorso G, Varotto C et al. (2017) The MTP1 promoters from Arabidopsis halleri reveal cis-regulating elements for the evolution of metal tolerance. New Phytol 214:1614-1630

Fernando DR, Bakkaus EJ, Perrier N et al. (2006a) Manganese accumulation in the leaf mesophyll of four tree species: a PIXE/EDAX localization study. New Phytol 171:751-757

Fernando DR, Batianoff GN, Baker AJM, Woodrow IE (2006b) In vivo localization of manganese in the hyperaccumulator Gossia bidwillii (Benth.) N. Snow \& Guymer (Myrtaceae) by cryoSEM/EDAX. Plant Cell Env 29:1012-1020

Fernando DR, Marshall A, Baker AJM, Mizuno T (2013) Microbeam methodologies as powerful tools in manganese hyperaccumulation research: present status and future directions. Front Plant Sci $4: 9$

Fernando DR, Woodrow IE, Baker AJM, Marshall AT (2012) Plant homeostasis of foliar manganese sinks: specific variation in hyperaccumulators. Planta 236:1459-1470

Filatov V, Dowdle J, Smirnoff N et al. (2007) A quantitative trait loci analysis of zinc hyperaccumulation in Arabidopsis halleri. New Phytol 174:580-590

Filatov V, Dowdle J, Smirnoff N et al. (2006) Comparison of gene expression in segregating families identifies genes and genomic regions involved in a novel adaptation, zinc hyperaccumulation. Mol Ecol 15:3045-3059

Fones H, Davis CAR, Rico A et al. (2010) Metal hyperaccumulation armors plants against disease. PLoS Pathog 6:e1001093 
Franz KJ (2013) Clawing back: Broadening the notion of metal chelators in medicine. Curr Opin Chem Biol 17:143-149

Freeman JL, Tamaoki M, Stushnoff C et al. (2010) Molecular mechanisms of selenium tolerance and hyperaccumulation in Stanleya pinnata. Plant Physiol 153:1630-1652

Frérot H, Faucon MP, Willems G et al. (2010) Genetic architecture of zinc hyperaccumulation in Arabidopsis halleri: the essential role of QTL x environment interactions. New Phytol 187:355-367

Fukuda N, Kitajima N, Terada Y et al. (2020) Visible cellular distribution of cadmium and zinc in the hyperaccumulator Arabidopsis halleri ssp. gemmifera determined by 2-D X-ray fluorescence imaging using high-energy synchrotron radiation. Metallomics 12:193-203

Gao J, Sun L, Yang X, Liu J-X (2013) Transcriptomic analysis of cadmium stress response in the heavy metal hyperaccumulator Sedum alfredii Hance. PLoS One 8:e64643

Garcia de la Torre VS, Majorel-Loulergue C, Gonzalez DA et al. (2018) Wide cross-species RNASeq comparison reveals a highly conserved role for Ferroportins in nickel hyperaccumulation in plants. bioRxiv 420729

Gendre D, Czernic P, Conejero G et al. (2007) TcYSL3, a member of the YSL gene family from the hyper-accumulator Thlaspi caerulescens, encodes a nicotianamine-Ni/Fe transporter. Plant J 49:1-15

Ghaderian SM, Ghasemi R, Hajihashemi F (2015) Interaction of nickel and manganese in uptake, translocation and accumulation by the nickel-hyperaccumulator plant, Alyssum bracteatum (Brassicaceae). Aust J Bot 63:47-55

Ghaderian YSM, Lyon AJE, Baker AJM (2000) Seedling mortality of metal hyperaccumulator plants resulting from damping off by Pythium spp. New Phytol 146:219-224

Gonneau C, Genevois N, Frérot H et al. (2014) Variation of trace metal accumulation, major nutrient uptake and growth parameters and their correlations in 22 populations of Noccaea caerulescens.

Plant Soil 384:271-287 
Gustin JL, Loureiro ME, Kim D et al. (2009) MTP1-dependent Zn sequestration into shoot vacuole's suggests dual roles in $\mathrm{Zn}$ tolerance and accumulation in $\mathrm{Zn}$ hyperaccumulating plants. Plant $\mathrm{J}$ $57: 1116-1127$

Halimaa P, Blande D, Aarts MGM et al. (2014a) Comparative transcriptome analysis of the metal hyperaccumulator Noccaea caerulescens. Front Plant Sci 5:213

Halimaa P, Blande D, Baltzi E et al. (2019) Transcriptional effects of cadmium on iron homeostasis differ in calamine accessions of Noccaea caerulescens. Plant J 97:306-320

Halimaa P, Lin YF, Ahonen VH et al. (2014b) Gene expression differences between Noccaea caerulescens ecotypes help to identify candidate genes for metal phytoremediation. Env Sci Technol $48: 3344-3353$

Hammond JP, Bowen H, White PJ et al. (2006) A comparison of Thlaspi caerulescens and Thlaspi arvense shoot transcriptomes. New Phytol 170:239-260

Han X, Yin H, Song X et al. (2016) Integration of small RNAs, degradome and transcriptome sequencing in hyperaccumulator Sedum alfredii uncovers a complex regulatory network and provides insights into cadmium phytoremediation. Plant Biotechnol J 14:1470-1483

Hanikenne M, Baurain D (2014) Origin and evolution of metal p-Type ATPases in Plantae (Archaeplastida). Front Plant Sci 4:544

Hanikenne M, Kroymann J, Trampczynska A et al. (2013) Hard selective sweep and ectopic gene conversion in a gene cluster affording environmental adaptation. PLoS Genet 9:e1003707

Hanikenne M, Nouet C (2011) Metal hyperaccumulation and hypertolerance: a model for plant evolutionary genomics. Curr Opin Plant Biol 14:252-259

Hanikenne M, Talke IN, Haydon MJ et al. (2008) Evolution of metal hyperaccumulation required cis-regulatory changes and triplication of HMA4. Nature 453:391-395 
Honjo MN, Kudoh H (2019) Arabidopsis halleri: a perennial model system for studying population differentiation and local adaptation. AoB Plants 11: plz076

Höreth S, Pongrac P, van Elteren JT et al. (2020) Arabidopsis halleri shows hyperbioindicator behaviour for $\mathrm{Pb}$ and leaf $\mathrm{Pb}$ accumulation spatially separated from $\mathrm{Zn}$. New Phytol 226:492-506

Hörger AC, Fones HN, Preston GM (2013) The current status of the elemental defense hypothesis in relation to pathogens. Front Plant Sci 4:395

Hussain D, Haydon MJ, Wang Y et al. (2004) P-type ATPase heavy metal transporters with roles in essential zinc homeostasis in Arabidopsis. Plant Cell 16:1327-1339

Idris R, Kuffner M, Bodrossy L et al. (2006) Characterization of Ni-tolerant methylobacteria associated with the hyperaccumulating plant Thlaspi goesingense and description of Methylobacterium goesingense sp. nov. Syst Appl Microbiol 29:634-644

Idris R, Trifonova R, Puschenreiter M et al. (2004) Bacterial communities associated with flowering plants of the Ni hyperaccumulator Thlaspi goesingense. Applied Environ Microbiol 70:2667-2677

Ingle RA, Mugford ST, Rees JD et al. (2005) Constitutively high expression of the histidine biosynthetic pathway contributes to nickel tolerance in hyperaccumulator plants. Plant Cell 17:20892106

Ingle RA, Mugford ST, Rees JD et al. (2005) Constitutively high expression of the histidine biosynthetic pathway contributes to nickel tolerance in hyperaccumulator plants. Plant Cell 17:2089210

Isaure MP, Huguet S, Meyer CL et al. (2015) Evidence of various mechanisms of Cd sequestration in the hyperaccumulator Arabidopsis halleri, the non-accumulator Arabidopsis lyrata, and their progenies by combined synchrotron-based techniques. J Exp Bot 66:3201-3214

Kajala K, Walker KL, Mitchell GS et al. (2019) Real-time whole-plant dynamics of heavy metal transport in Arabidopsis halleri and Arabidopsis thaliana by gamma-ray imaging. Plant Direct 3:e00131 
Karam M-J, Souleman D, Schvartzman MS et al. (2019) Genetic architecture of a plant adaptive trait: QTL mapping of intraspecific variation for tolerance to metal pollution in Arabidopsis halleri. Heredity (Edinb) 122:877-892

Kasprzak MM, Erxleben A, Ochocki J (2015) Properties and applications of flavonoid metal complexes. RSC Adv 5:45853-45877

Kerkeb L, Krämer U (2003) The role of free histidine in xylem loading of nickel in Alyssum lesbiacum and Brassica juncea. Plant Physiol 131:716-724

Kim D, Gustin JL, Lahner B et al. (2004) The plant CDF family member TgMTP1 from the Ni/Zn hyperaccumulator Thlaspi goesingense acts to enhance efflux of $\mathrm{Zn}$ at the plasma membrane when expressed in Saccharomyces cerevisiae. Plant J 39:237-251

Kobayashi T, Nozoye T, Nishizawa NK (2019) Iron transport and its regulation in plants. Free Radic Biol Med 133:11-20

Kopittke PM, Punshon T, Paterson DJ et al. (2018) Synchrotron-based X-ray fluorescence microscopy as a technique for imaging of elements in plants. Plant Physiol 178:507-523

Korshunova YO, Eide D, Gregg Clark W et al. (1999) The IRT1 protein from Arabidopsis thaliana is a metal transporter with a broad substrate range. Plant Mol Biol 40:37-44

Kozhevnikova AD, Seregin I V, Erlikh NT et al. (2014) Histidine-mediated xylem loading of zinc is a species-wide character in Noccaea caerulescens. New Phytol 203:508-519

Krämer U (2010) Metal hyperaccumulation in plants. Annu Rev Plant Biol 61:517-534

Krämer U (2005) MTP1 mops up excess zinc in Arabidopsis cells. Trends Plant Sci 10:313-315

Krämer U, Cotter-Howells JD, Charnock JM et al. (1996) Free histidine as a metal chelator in plants that accumulate nickel. Nature 379:635-638 
Krämer U, Pickering IJ, Prince RC et al. (2000) Subcellular localization and speciation of nickel in hyperaccumulator and non-accumulator Thlaspi species. Plant Physiol 122:1343-1354

Krämer U, Talke IN, Hanikenne M (2007) Transition metal transport. FEBS Lett 581:2263-2272

Küpper H, Lombi E, Zhao FJ et al. (2001) Cellular compartmentation of nickel in the hyperaccumulators Alyssum lesbiacum, Alyssum bertolonii and Thlaspi goesingense. J Exp Bot $52: 2291-2300$

Küpper H, Lombi E, Zhao FJ, McGrath SP (2000) Cellular compartmentation of cadmium and zinc in relation to other elements in the hyperaccumulator Arabidopsis halleri. Planta 212:75-84

Küpper H, Zhao FJ, McGrath SP (1999) Cellular compartmentation of zinc in leaves of the hyperaccumulator Thlaspi caerulescens. Plant Physiol 119:305-311

Lambers H, Hayes PE, Laliberte E et al. (2015) Leaf manganese accumulation and phosphorusacquisition efficiency. Trends Plant Sci 20:83-90

Leigh Broadhurst C, Tappero R, Maugel T et al. (2009) Interaction of nickel and manganese in accumulation and localization in leaves of the Ni hyperaccumulators Alyssum murale and Alyssum corsicum. Plant Soil 314:35-48

Leitenmaier B, Küpper H (2013) Compartmentation and complexation of metals in hyperaccumulator plants. Front Plant Sci 4:374

Lešková A, Zvarík M, Araya T, Giehl RFH (2019) Nickel toxicity targets cell wall-related processes and PIN2-mediated auxin transport to inhibit root elongation and gravitropic responses in Arabidopsis. Plant Cell Physiol 61:519-535

Li J, Gurajala HK, Wu L et al. (2018) Hyperaccumulator plants from China: a synthesis of the current state of knowledge. Environ Sci Technol 52:11980-11994

Li J, Jia Y, Dong R et al. (2019) Advances in the mechanisms of plant tolerance to manganese toxicity. Int J Mol Sci 20:5096 
Li T, Xu Z, Han X et al. (2012) Characterization of dissolved organic matter in the rhizosphere of hyperaccumulator Sedum alfredii and its effect on the mobility of zinc. Chemosphere 88:570-576

Liang J, Shohag MJI, Yang X et al. (2014) Role of sulfur assimilation pathway in cadmium hyperaccumulation by Sedum alfredii Hance. Ecotoxicol Environ Saf 100:159-165

Lima LW, Pilon-Smits EAH, Schiavon M (2018) Mechanisms of selenium hyperaccumulation in plants: A survey of molecular, biochemical and ecological cues. Biochim Biophys Acta - Gen Subj 1862:2343-2353

Lin YF, Hassan Z, Talukdar S et al. (2016) Expression of the ZNT1 zinc transporter from the metal hyperaccumulator Noccaea caerulescens confers enhanced zinc and cadmium tolerance and accumulation to Arabidopsis thaliana. PLoS One 11:e0149750

Lin YF, Liang HM, Yang SY et al. (2009) Arabidopsis IRT3 is a zinc-regulated and plasma membrane localized zinc/iron transporter. New Phytol 182:392-404

Liu H, Zhao H, Wu L et al. (2017) Heavy metal ATPase 3 (HMA3) confers cadmium hypertolerance on the cadmium/zinc hyperaccumulator Sedum plumbizincicola. New Phytol 215:687-698

Lombi E, Zhao F-J, Fuhrmann M et al. (2002) Arsenic distribution and speciation in the fronds of the hyperaccumulator Pteris vittata. New Phytol 156:195-203

Losfeld G, L'Huillier L, Fogliani B et al. (2015) Leaf age and soil-plant relationships: key factors for reporting trace-elements hyperaccumulation by plants and design applications. Env Sci Pollut Res Int $22: 5620-5632$

Lu L, Liao X, Labavitch J et al. (2014) Speciation and localization of Zn in the hyperaccumulator Sedum alfredii by extended X-ray absorption fine structure and micro-X-ray fluorescence. Plant Physiol Biochem 84:224-232

Lu L, Tian S, Zhang J et al. (2013) Efficient xylem transport and phloem remobilization of Zn in the hyperaccumulator plant species Sedum alfredii. New Phytol 198:721-731 
Lucisine P, Echevarria G, Sterckeman T et al. (2014) Effect of hyperaccumulating plant cover composition and rhizosphere-associated bacteria on the efficiency of nickel extraction from soil. Appl Soil Ecol 81:30-36

Luo S, Chen L, Chen J et al. (2011) Analysis and characterization of cultivable heavy metal-resistant bacterial endophytes isolated from Cd-hyperaccumulator Solanum nigrum L. and their potential use for phytoremediation. Chemosphere 85:1130-1138

Ma Y, Prasad MN V, Rajkumar M, Freitas H (2011a) Plant growth promoting rhizobacteria and endophytes accelerate phytoremediation of metalliferous soils. Biotechnol Adv 29:248-258

Ma Y, Rajkumar M, Luo Y, Freitas H (2011b) Inoculation of endophytic bacteria on host and nonhost plants - effects on plant growth and Ni uptake. J Hazard Mater 195:230-237

Mari S, Gendre D, Pianelli K et al. (2006) Root-to-shoot long-distance circulation of nicotianamine and nicotianamine-nickel chelates in the metal hyperaccumulator Thlaspi caerulescens. J Exp Bot $57: 4111-4122$

McNear Jr. DH, Chaney RL, Sparks DL (2010) The hyperaccumulator Alyssum murale uses complexation with nitrogen and oxygen donor ligands for Ni transport and storage. Phytochemistry $71: 188-200$

Meier SK, Adams N, Wolf M et al. (2018) Comparative RNA-seq analysis of nickel hyperaccumulating and non-accumulating populations of Senecio coronatus (Asteraceae). Plant J 95:1023-1038

Mengoni A, Pini F, Huang L-N et al. (2009a) Plant-by-plant variations of bacterial communities associated with leaves of the nickel hyperaccumulator Alyssum bertolonii Desv. Microb Ecol 58:660-667

Mengoni A, Schat H, Vangronsveld J (2009b) Plants as extreme environments? Ni-resistant bacteria and Ni-hyperaccumulators of serpentine flora. Plant Soil 331:5-16 
Menguer PK, Farthing E, Peaston KA et al. (2013) Functional analysis of the rice vacuolar zinc transporter OsMTP1. J Exp Bot 64:2871-2883

Merlot S, Hannibal L, Martins S et al. (2014) The metal transporter PgIREG1 from the hyperaccumulator Psychotria gabriellae is a candidate gene for nickel tolerance and accumulation. $\mathrm{J}$ Exp Bot 65:1551-1564

Meyer C-L, Juraniec M, Huguet S et al. (2015) Intraspecific variability of cadmium tolerance and accumulation, and cadmium-induced cell wall modifications in the metal hyperaccumulator Arabidopsis halleri. J Exp Bot 66:3215-3227

Meyer C-L, Kostecka AA, Saumitou-Laprade P et al. (2010) Variability of zinc tolerance among and within populations of the pseudometallophyte species Arabidopsis halleri and possible role of directional selection. New Phytol 185:130-142

Meyer C-L, Pauwels M, Briset L et al. (2016) Potential preadaptation to anthropogenic pollution: evidence from a common quantitative trait locus for zinc and cadmium tolerance in metallicolous and nonmetallicolous accessions of Arabidopsis halleri. New Phytol 212:934-943

Meyer C-L, Verbruggen N (2012) The use of the model species Arabidopsis halleri towards phytoextraction of cadmium polluted soils. J Biotechnol 30:9-14

Meyer C-L, Vitalis R, Saumitou-Laprade P, Castric V (2009) Genomic pattern of adaptive divergence in Arabidopsis halleri, a model species for tolerance to heavy metal. Mol Ecol 18:2050 2062

Milner MJ, Craft E, Yamaji N et al. (2012) Characterization of the high affinity Zn transporter from Noccaea caerulescens, NcZNT1, and dissection of its promoter for its role in Zn uptake and hyperaccumulation. New Phytol 195:113-123

Milner MJ, Kochian L V (2008) Investigating heavy-metal hyperaccumulation using Thlaspi caerulescens as a model system. Ann Bot 102:3-13 
Milner MJ, Mitani-Ueno N, Yamaji N et al. (2014) Root and shoot transcriptome analysis of two ecotypes of Noccaea caerulescens uncovers the role of NcNramp1 in Cd hyperaccumulation. Plant $\mathbf{J}$ $78: 398-410$

Mirouze M, Sels J, Richard O et al. (2006) A putative novel role for plant defensins: a defensin from the zinc hyper-accumulating plant, Arabidopsis halleri, confers zinc tolerance. Plant J 47:329-342

Mizuno T, Usui K, Horie K et al. (2005) Cloning of three ZIP/Nramp transporter genes from a Ni hyperaccumulator plant Thlaspi japonicum and their Ni2+-transport abilities. Plant Physiol Biochem 43:793-801

Mizuno T, Usui K, Nishida S et al. (2007) Investigation of the basis for Ni tolerance conferred by the expression of TjZnt1 and TjZnt2 in yeast strains. Plant Physiol Biochem 45:371-378

Molins H, Michelet L, Lanquar Vi et al. (2013) Mutants impaired in vacuolar metal mobilization identify chloroplasts as a target for cadmium hypersensitivity in Arabidopsis thaliana. Plant Cell Environ 36:804-817

Molitor M, Dechamps C, Gruber W, Meerts P (2005) Thlaspi caerulescens on nonmetalliferous soil in Luxembourg: ecological niche and genetic variation in mineral element composition. New Phytol $165: 503-512$

Monsant AC, Kappen P, Wang Y et al. (2011) In vivo speciation of zinc in Noccaea caerulescens in response to nitrogen form and zinc exposure. Plant Soil 348:167

Morel M, Crouzet J, Gravot A et al. (2009) AtHMA3, a P1B-ATPase allowing Cd/Zn/Co/Pb vacuolar storage in Arabidopsis. Plant Physiol 149:894-904

Morrissey J, Baxter IR, Lee J et al. (2009) The ferroportin metal efflux proteins function in iron and cobalt homeostasis in Arabidopsis. Plant Cell 21:3326-3338

Muehe EM, Weigold P, Adaktylou IJ et al. (2015) Rhizosphere microbial community composition affects cadmium and zinc uptake by the metal-hyperaccumulating plant Arabidopsis halleri. Appl Environ Microbiol 81:2173-2181 
Nguyen NNT, Ranwez V, Vile D et al. (2014) Evolutionary tinkering of the expression of PDF1s suggests their joint effect on zinc tolerance and the response to pathogen attack. Front Plant Sci 5:70

Nishida S, Aisu A, Mizuno T (2012) Induction of IRT1 by the nickel-induced iron-deficient response in Arabidopsis. Plant Signal Behav 7:329-331

Nishida S, Tsuzuki C, Kato A et al. (2011) AtIRT1, the primary iron uptake transporter in the root, mediates excess nickel accumulation in Arabidopsis thaliana. Plant Cell Physiol 52:1433-1442

Nouet C, Charlier JB, Carnol M et al. (2015) Functional analysis of the three HMA4 copies of the metal hyperaccumulator Arabidopsis halleri. J Exp Bot 66:5783-5795

Nowak J, Frérot H, Faure N et al. (2018) Can zinc pollution promote adaptive evolution in plants? Insights from a one-generation selection experiment. J Exp Bot 69:5561-5572

O’ Lochlainn S, Bowen HC, Fray RG, et al. (2011) Tandem quadruplication of HMA4 in the zinc (Zn) and cadmium (Cd) hyperaccumulator Noccaea caerulescens. PLoS One 6:e17814

Oomen RJ, Seveno-Carpentier E, Ricodeau N et al. (2011) Plant defensin AhPDF1.1 is not secreted in leaves but it accumulates in intracellular compartments. New Phytol 192:140-150

Oomen RJFJ, Wu J, Lelièvre F et al. (2009) Functional characterization of NRAMP3 and NRAMP4 from the metal hyperaccumulator Thlaspi caerulescens. New Phytol 181:637-65

Paape T, Briskine R V, Halstead-Nussloch G et al. (2018) Patterns of polymorphism and selection in the subgenomes of the allopolyploid Arabidopsis kamchatica. Nat Commun 9:3909

Pankievicz VC, Camilios-Neto D, Bonato P et al. (2016) RNA-seq transcriptional profiling of Herbaspirillum seropedicae colonizing wheat (Triticum aestivum) roots. Plant Mol Biol 90:589-603

Papoyan A, Kochian L V (2004) Identification of Thlaspi caerulescens genes that may be involved in heavy metal hyperaccumulation and tolerance. Characterization of a novel heavy metal transporting ATPase. Plant Physiol 136:3814-3823 
Pauwels M, Frérot H, Bonnin I, Saumitou-Laprade P (2006) A broad-scale analysis of population differentiation for $\mathrm{Zn}$ tolerance in an emerging model species for tolerance study: Arabidopsis halleri (Brassicaceae). J Evol Biol 19:1838-1850

Pauwels M, Roosens N, Frérot H, Saumitou-Laprade P (2008) When population genetics serves genomics: putting adaptation back in a spatial and historical context. Curr Opin Plant Biol 11:129134

Pauwels M, Vekemans X, Godé C et al. (2012) Nuclear and chloroplast DNA phylogeography reveals vicariance among European populations of the model species for the study of metal tolerance, Arabidopsis halleri (Brassicaceae). New Phytol 193:916-928

Pedersen CNS, Axelsen KB, Harper JF, Palmgren MG (2012) Evolution of plant P-type ATPases. Front Plant Sci 3:31

Peer WA, Mamoudian M, Lahner B et al. (2003) Identifying model metal hyperaccumulating plants: germplasm analysis of 20 Brassicaceae accessions from a wide geographical area. New Phytol $159: 421-430$

Pence NS, Larsen PB, Ebbs SD et al. (2000) The molecular physiology of heavy metal transport in the Zn/Cd hyperaccumulator Thlaspi caerulescens. Proc Natl Acad Sci U S A 97:4956-60

Peng JS, Wang YJ, Ding G et al. (2017) A pivotal role of cell wall in cadmium accumulation in the Crassulaceae hyperaccumulator Sedum plumbizincicola. Mol Plant 10:771-774

Persans MW, Nieman K, Salt DE (2001) Functional activity and role of cation-efflux family members in Ni hyperaccumulation in Thlaspi goesingense. Proc Natl Acad Sci U S A 98:999510000

Persans MW, Yan X, Patnoe JM et al. (1999) Molecular dissection of the role of histidine in nickel hyperaccumulation in Thlaspi goesingense (Halácsy). Plant Physiol 121:1117-1126

Pianelli K, Mari S, Marques L et al. (2005) Nicotianamine over-accumulation confers resistance to nickel in Arabidopsis thaliana. Transgenic Res 14:739-748 
Pickering IJ, Wright C, Bubner B et al. (2003) Chemical form and distribution of selenium and sulfur in the selenium hyperaccumulator Astragalus bisulcatus. Plant Physiol 131:1460-1467

Pittman JK (2005) Managing the manganese: molecular mechanisms of manganese transport and homeostasis. New Phytol 167:733-742

Polacco JC, Mazzafera P, Tezotto T (2013) Opinion- Nickel and urease in plants: still many knowledge gaps. Plant Sci 199-200:79-90

Pongrac P, Serra TS, Castillo-Michel H et al. (2018) Cadmium associates with oxalate in calcium oxalate crystals and competes with calcium for translocation to stems in the cadmium bioindicator Gomphrena claussenii. Metallomics 10:1576-1584

Pottier M, Oomen R, Picco C et al. (2015) Identification of mutations allowing Natural Resistance Associated Macrophage Proteins (NRAMP) to discriminate against cadmium. Plant J 83:625-637

Preite V, Sailer C, Syllwasschy L et al. (2019) Convergent evolution in Arabidopsis halleri and Arabidopsis arenosa on calamine metalliferous soils. Philos Trans R Soc B Biol Sci 374:20180243.

Rascio N, Navari-Izzo F (2011) Heavy metal hyperaccumulating plants: how and why do they do it? And what makes them so interesting? Plant Sci 180:169-181

Reeves RD, Baker AJM, Jaffré T et al. (2018) A global database for plants that hyperaccumulate metal and metalloid trace elements. New Phytol 218:407-411

Reeves RD, Schwartz C, Morel JL, Edmondson J (2001) Distribution and metal-accumulating behavior of Thlaspi caerulescens and associated metallophytes in France. Int J Phytoremediation $3: 145-172$

Reinhold-Hurek B, Hurek T (2011) Living inside plants: bacterial endophytes. Curr Opin Plant Biol $14: 435-443$

Rellan-Alvarez R, Abadia J, Alvarez-Fernandez A (2008) Formation of metal-nicotianamine complexes as affected by $\mathrm{pH}$, ligand exchange with citrate and metal exchange. A study by 
electrospray ionization time-of-flight mass spectrometry. Rapid Commun Mass Spectrom 22:15531562

Reynolds RJB, Pilon-Smits EAH (2018) Plant selenium hyperaccumulation - ecological effects and potential implications for selenium cycling and community structure. Biochim Biophys Acta - Gen Subj 1862:2372-2382

Ricachenevsky FK, Menguer PK, Sperotto RA, Fett JP (2015) Got to hide your Zn away: Molecular control of Zn accumulation and biotechnological applications. Plant Sci 236:1-17

Richau KH, Kozhevnikova AD, Seregin IV et al. (2009) Chelation by histidine inhibits the vacuolar sequestration of nickel in roots of the hyperaccumulator Thlaspi caerulescens. New Phytol 183:106116.

Rogers EE, Eide DJ, Guerinot ML (2000) Altered selectivity in an Arabidopsis metal transporter. Proc Natl Acad Sci U S A 97:12356-12360

Rogers EE, Guerinot ML (2002) FRD3, a member of the multidrug and toxin efflux family, controls iron deficiency responses in Arabidopsis. Plant Cell 14:1787-1799

Roosens N, Verbruggen N, Meerts P et al. (2003) Natural variation in cadmium hyperaccumulation and its relationship to metal hyperaccumulation for seven populations of Thlaspi caerulescens from western Europe. Plant Cell Env 26:1657-1672

Roosens NH, Willems G, Saumitou-Laprade P (2008) Using Arabidopsis to explore zinc tolerance and hyperaccumulation. Trends Plant Sci 13:208-215

Roux C, Castric V, Pauwels M et al. (2011) Does speciation between Arabidopsis halleri and Arabidopsis lyrata coincide with major changes in a molecular target of adaptation? PLoS One 6:e26872

Sailer C, Babst-Kostecka A, Fischer MC et al. (2018) Transmembrane transport and stress response genes play an important role in adaptation of Arabidopsis halleri to metalliferous soils. Sci Rep 8:16085 
Sarret G, Saumitou-Laprade P, Bert V et al. (2002) Forms of zinc accumulated in the hyperaccumulator Arabidopsis halleri. Plant Physiol 130:1815-1826

Sarret G, Smits E, Michel HC et al. (2013) Use of synchrotron-based techniques to elucidate metal uptake and metabolism in plants. In: Sparks DL (ed) Advances in Agronomy, Vol 119. Elsevier Academic Press Inc, San Diego, pp 1-82

Sarret G, Willems G, Isaure MP et al. (2009) Zinc distribution and speciation in Arabidopsis halleri $\mathrm{x}$ Arabidopsis lyrata progenies presenting various zinc accumulation capacities. New Phytol $184: 581-595$

Schaaf G, Honsbein A, Meda AR et al. (2006) AtIREG2 encodes a tonoplast transport protein involved in iron-dependent nickel detoxification in Arabidopsis thaliana roots. J Biol Chem $281: 25532-25540$

Schaumlöffel D, Ouerdane L, Bouyssiere B, Lobinski R (2003) Speciation analysis of nickel in the latex of a hyperaccumulating tree Sebertia acuminata by HPLC and CZE with ICP MS and electrospray MS-MS detection. J Anal At Spectrom 18:120-127

Schiavon M, Pilon-Smits EAH (2017) The fascinating facets of plant selenium accumulation biochemistry, physiology, evolution and ecology. New Phytol 213:1582-1596

Schiavon M, Pilon M, Malagoli M, Pilon-Smits EAH (2015) Exploring the importance of sulfate transporters and ATP sulphurylases for selenium hyperaccumulation - a comparison of Stanleya pinnata and Brassica juncea (Brassicaceae). Front Plant Sci 6:1-13

Schvartzman MS, Corso M, Fataftah N et al. (2018) Adaptation to high zinc depends on distinct mechanisms in metallicolous populations of Arabidopsis halleri. New Phytol 218:269-282

Sessitsch A, Hardoim P, Döring J,et al. (2012) Functional characteristics of an endophyte community colonizing rice roots as revealed by metagenomic analysis. Mol Plant Microbe Interact 25:28-36 
Shahzad Z, Gosti F, Frérot H et al. (2010) The five AhMTP1 zinc transporters undergo different evolutionary fates towards adaptive evolution to zinc tolerance in Arabidopsis halleri. PLoS Genet 6:e1000911

Shahzad Z, Ranwez V, Fizames C et al. (2013) Plant Defensin type 1 (PDF1): protein promiscuity and expression variation within the Arabidopsis genus shed light on zinc tolerance acquisition in Arabidopsis halleri. New Phytol 200:820-833

Shao JF, Yamaji N, Shen RF, Ma JF (2017) The key to Mn homeostasis in plants: regulation of Mn transporters. Trends Plant Sci 22:215-224

Shibagaki N, Rose A, McDermott JP et al. (2002) Selenate-resistant mutants of Arabidopsis thaliana identify Sultr1;2, a sulfate transporter required for efficient transport of sulfate into roots. Plant J $29: 475-486$

Socha AL, Guerinot ML (2014) Mn-euvering manganese: the role of transporter gene family members in manganese uptake and mobilization in plants. Front Plant Sci 5:106

Stein RJ, Höreth S, de Melo JRF et al. (2017) Relationships between soil and leaf mineral composition are element-specific, environment-dependent and geographically structured in the emerging model Arabidopsis halleri. New Phytol 213:1274-1286

Sterckeman T, Cazes Y, Sirguey C (2019) Breeding the hyperaccumulator Noccaea caerulescens for trace metal phytoextraction: first results of a pure-line selection. Int J Phytoremediation 21:448-455.

Suryawanshi V, Talke IN, Weber M et al. (2016) Between-species differences in gene copy number are enriched among functions critical for adaptive evolution in Arabidopsis halleri. BMC Genomics $17: 1034$

Szopiński M, Sitko K, Gieroń Ż et al. (2019) Toxic effects of Cd and Zn on the photosynthetic apparatus of the Arabidopsis halleri and Arabidopsis arenosa pseudo-metallophytes. Front Plant Sci $10: 748$ 
Talke IN, Hanikenne M, Krämer U (2006) Zinc-dependent global transcriptional control, transcriptional deregulation, and higher gene copy number for genes in metal homeostasis of the hyperaccumulator Arabidopsis halleri. Plant Physiol 142:148-167

Thomine S, Vert G (2013) Iron transport in plants: better be safe than sorry. Curr Opin Plant Biol $16: 322-327$

Tian S, Lu L, Labavitch J et al. (2011) Cellular sequestration of cadmium in the hyperaccumulator plant species Sedum alfredii. Plant Physiol 157:1914-1925

Tsednee M, Yang S-C, Lee D-C, Yeh K-C (2014) Root-secreted nicotianamine from Arabidopsis halleri facilitates zinc hypertolerance by regulating zinc bioavailability. Plant Physiol 166:839-852

Turner TL, Bourne EC, Von Wettberg EJ,et al. (2010) Population resequencing reveals local adaptation of Arabidopsis lyrata to serpentine soils. Nat Genet 42:260-263

Ueno D, Milner MJ, Yamaji N et al. (2011) Elevated expression of TcHMA3 plays a key role in the extreme Cd tolerance in a Cd-hyperaccumulating ecotype of Thlaspi caerulescens. Plant J 66:852862

Uraguchi S, Weber M, Clemens S (2019) Elevated root nicotianamine concentrations are critical for Zn hyperaccumulation across diverse edaphic environments. Plant Cell Environ 42:2003-2014

van de Mortel JE, Almar Villanueva L, Schat H et al. (2006) Large expression differences in genes for iron and zinc homeostasis, stress response, and lignin biosynthesis distinguish roots of Arabidopsis thaliana and the related metal hyperaccumulator Thlaspi caerulescens. Plant Physiol $142: 1127-1147$

van de Mortel JE, Schat H, Moerland PD, et al. (2008) Expression differences for genes involved in lignin, glutathione and sulphate metabolism in response to cadmium in Arabidopsis thaliana and the related Zn/Cd-hyperaccumulator Thlaspi caerulescens. Plant Cell Env 31:301-324

van der Ent A, Baker AJM, Reeves RD et al. (2013) Hyperaccumulators of metal and metalloid trace elements: facts and fiction. Plant Soil 362:319-334 
van der Ent A, Przybyłowicz WJ, de Jonge MD et al. (2018) X-ray elemental mapping techniques for elucidating the ecophysiology of hyperaccumulator plants. New Phytol 218:432-452

van der Ent A, Spiers KM, Brueckner D et al. (2019) Spatially-resolved localization and chemical speciation of nickel and zinc in Noccaea tymphaea and Bornmuellera emarginata. Metallomics $11: 2052-2065$

van der Pas L, Ingle AR (2019) Towards an understanding of the molecular basis of nickel hyperaccumulation in plants. Plants 8:11

van der Weerden NL, Anderson MA (2013) Plant defensins: Common fold, multiple functions. Fungal Biol Rev 26:121-131

Verbruggen N, Hanikenne M, Clemens S (2013a) A more complete picture of metal hyperaccumulation through next-generation sequencing technologies. Front Plant Sci 4:388.

Verbruggen N, Hermans C, Schat H (2009) Molecular mechanisms of metal hyperaccumulation in plants. New Phytol 181:759-776

Verbruggen N, Juraniec M, Baliardini C, Meyer C-L (2013b) Tolerance to cadmium in plants: the special case of hyperaccumulators. Biometals 26:633-638

Vert G, Grotz N, Dedaldechamp F et al. (2002) IRT1, an Arabidopsis transporter essential for iron uptake from the soil and for plant growth. Plant Cell 14:1223-1233

Villafort Carvalho MT, Amaral DC, Guilherme LR, Aarts MGM (2013) Gomphrena claussenii, the first South-American metallophyte species with indicator-like $\mathrm{Zn}$ and $\mathrm{Cd}$ accumulation and extreme metal tolerance. Front Plant Sci 4:180

Villafort Carvalho MT, Pongrac P, Mumm R et al. (2015) Gomphrena claussenii, a novel metalhypertolerant bioindicator species, sequesters cadmium, but not zinc, in vacuolar oxalate crystals. New Phytol 208:763-775 
Visioli G, D’Egidio S, Vamerali T et al. (2014) Culturable endophytic bacteria enhance Ni translocation in the hyperaccumulator Noccaea caerulescens. Chemosphere 117:538-544

Visioli G, Vamerali T, Mattarozzi M et al. (2015) Combined endophytic inoculants enhance nickel phytoextraction from serpentine soil in the hyperaccumulator Noccaea caerulescens. Front Plant Sci $6: 1-12$

Wang J, Cappa JJ, Harris JP et al. (2018) Transcriptome-wide comparison of selenium hyperaccumulator and nonaccumulator Stanleya species provides new insight into key processes mediating the hyperaccumulation syndrome. Plant Biotechnol J 16:1582-1594

Wang J, Xiong Y, Zhang J et al. (2020) Naturally selected dominant weeds as heavy metal accumulators and excluders assisted by rhizosphere bacteria in a mining area. Chemosphere $243: 125365$

Weber M, Harada E, Vess C et al. (2004) Comparative microarray analysis of Arabidopsis thaliana and Arabidopsis halleri roots identifies nicotianamine synthase, a ZIP transporter and other genes as potential metal hyperaccumulation factors. Plant J 37:269-281

Weber M, Trampczynska A, Clemens S (2006) Comparative transcriptome analysis of toxic metal responses in Arabidopsis thaliana and the $\mathrm{Cd} 2+$-hypertolerant facultative metallophyte Arabidopsis halleri. Plant Cell Env 29:950-963

Wei W, Chai T, Zhang Y et al. (2009) The Thlaspi caerulescens NRAMP homologue TcNRAMP3 is capable of divalent cation transport. Mol Biotechnol 41:15-21

White PJ (2016) Selenium accumulation by plants. Ann Bot 117:217-235

Willems G, Dräger DB, Courbot M et al. (2007) The genetic basis of zinc tolerance in the metallophyte Arabidopsis halleri ssp. halleri (Brassicaceae): an analysis of quantitative trait loci. Genetics 176:659-674 
Willems G, Frérot H, Gennen J et al. (2010) Quantitative trait loci analysis of mineral element concentrations in an Arabidopsis halleri x Arabidopsis lyrata petraea F2 progeny grown on cadmium-contaminated soil. New Phytol 187:368-379

Wong CKE, Cobbett CS (2009) HMA P-type ATPases are the major mechanism for root-to-shoot Cd translocation in Arabidopsis thaliana. New Phytol 181:71-78

Wu J, Zhao F-J, Ghandilyan A et al. (2009) Identification and functional analysis of two ZIP metal transporters of the hyperaccumulator Thlaspi caerulescens. Plant Soil 325:79

Wu LH, Liu YJ, Zhou SB et al. (2013) Sedum plumbizincicola X.H. Guo et S.B. Zhou ex L.H. Wu (Crassulaceae): A new species from Zhejiang Province, China. Plant Syst Evol 299:487-498

Wu Y, Ma L, Liu Q et al. (2020a) The plant-growth promoting bacteria promote cadmium uptake by inducing a hormonal crosstalk and lateral root formation in a hyperaccumulator plant Sedum alfredii. J Hazard Mater 395:122661

Wu Y, Ma L, Liu Q et al. (2020b) Pseudomonas fluorescens promote photosynthesis, carbon fixation and cadmium phytoremediation of hyperaccumulator Sedum alfredii. Sci Total Environ 726:138554

Wycisk K, Kim EJ, Schroeder JI, Krämer U (2004) Enhancing the first enzymatic step in the histidine biosynthesis pathway increases the free histidine pool and nickel tolerance in Arabidopsis thaliana. FEBS Lett 578:128-134

Yang Q, Ma X, Luo S et al. (2018) SaZIP4, an uptake transporter of Zn/Cd hyperaccumulator Sedum alfredii Hance. Environ Exp Bot 155:107-117

Yang X, Li T, Yang J et al. (2006) Zinc compartmentation in root, transport into xylem, and absorption into leaf cells in the hyperaccumulating species of Sedum alfredii Hance. Planta 224:185195

Yang XE, Long XX, Ye HB et al. (2004) Cadmium tolerance and hyperaccumulation in a new Znhyperaccumulating plant species (Sedum alfredii Hance). Plant Soil 259:181-189 
Yogeeswaran K, Frary A, York TL et al. (2005) Comparative genome analyses of Arabidopsis spp.: Inferring chromosomal rearrangement events in the evolutionary history of $A$. thaliana. Genome Res $15: 505-515$

Yokosho K, Yamaji N, Ueno D et al. (2009) OsFRDL1 is a citrate transporter required for efficient translocation of iron in rice. Plant Physiol 149:297-305

Zhang M, Senoura T, Yang X, Nishizawa NK (2011) Functional analysis of metal tolerance proteins isolated from $\mathrm{Zn} / \mathrm{Cd}$ hyperaccumulating ecotype and non-hyperaccumulating ecotype of Sedum alfredii Hance. FEBS Lett 585:2604-2609

Zhang Z, Yu Q, Du H, et al. (2016) Enhanced cadmium efflux and root-to-shoot translocation are conserved in the hyperaccumulator Sedum alfredii (Crassulaceae family). FEBS Lett 590:1757-1764

Zhao H, Wang L, Zhao F-J et al. (2019) SpHMA1 is a chloroplast cadmium exporter protecting photochemical reactions in the Cd hyperaccumulator Sedum plumbizincicola. Plant Cell Environ 42:1112-1124 


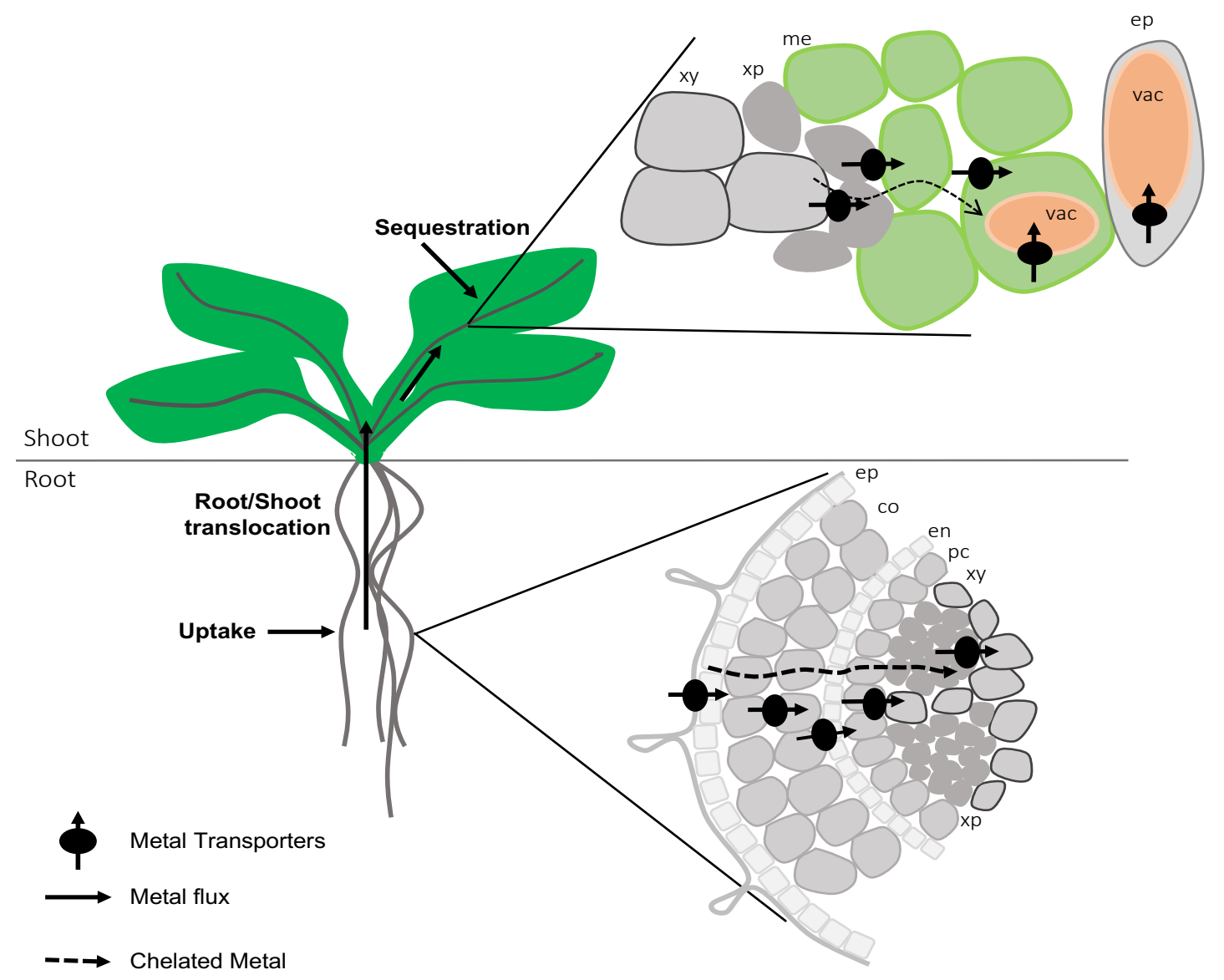

Figure 1

Figure 8.1. Model of the physiology of metal hyperaccumulation and hypertolerance. Enhanced metal uptake and radial transport in roots, xylem loading/unloading and vacuolar storage in shoots all make major contributions to the traits. In roots, it is possible that the metal can travel in the apoplasm up to the endodermis cell layer before cellular uptake (not represented). Note that the tissue (epidermis or mesophyll) involved in metal storage varies depending on the species and the metal (see text). co: cortex; en: endodermis; ep: epidermis; me: mesophyll; Zinc-NA: Zinc-Nicotianamine chelates; pc: pericycle; vac: vacuole; xp: xylem parenchyma; xy: xylem. Figure modified from (Hanikenne and Nouet 2011). 


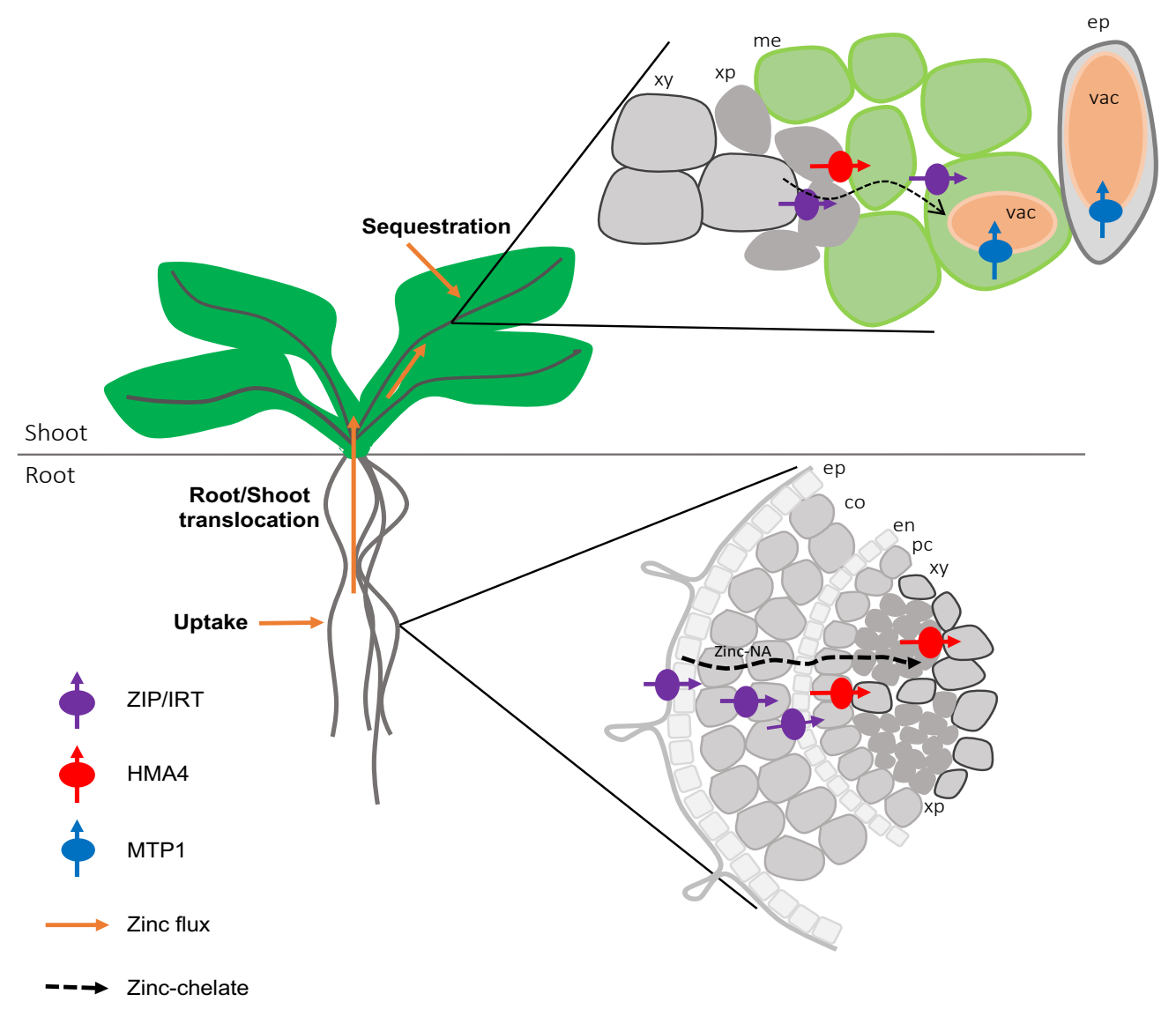

Figure 2

Figure 8.2. Model for Zn hyperaccumulation and hypertolerance in the Brassicaceae A. halleri and $N$. caerulescens. Enhanced functions of ZIP transporters in cellular uptake, of the P-type ATPase HMA4 in xylem loading/unloading and of MTP1 in vacuolar storage all make major contributions to the traits. The exact functions and localizations of individual ZIPs are unknown. In roots, the metal chelator nicotianamine (NA) possibly favours $\mathrm{Zn}$ radial transport towards the xylem by symplastic intercellular mobility of $\mathrm{Zn}$ by either allowing $\mathrm{Zn}$ movement through plasmodesmata and/or preventing vacuolar storage. Vacuolar storage in shoots occurs in the epidermis in $N$. caerulescens and in the mesophyll in A. halleri. Additional metal homeostasis genes that are highly expressed in both hyperaccumulators are discussed in the text. Note that similar mechanisms have been identified as more active in a metal hyperaccumulating population of the Crassulaceae $S$. alfredii compared to a non-accumulating population or in or S. plumbizincola. co: cortex; en: endodermis; ep: epidermis; me: mesophyll; Zinc-NA: Zinc-Nicotianamine chelates; pc: pericycle; vac: vacuole; $x p$ : xylem parenchyma; xy: xylem. Figure modified from (Hanikenne and Nouet 2011). 


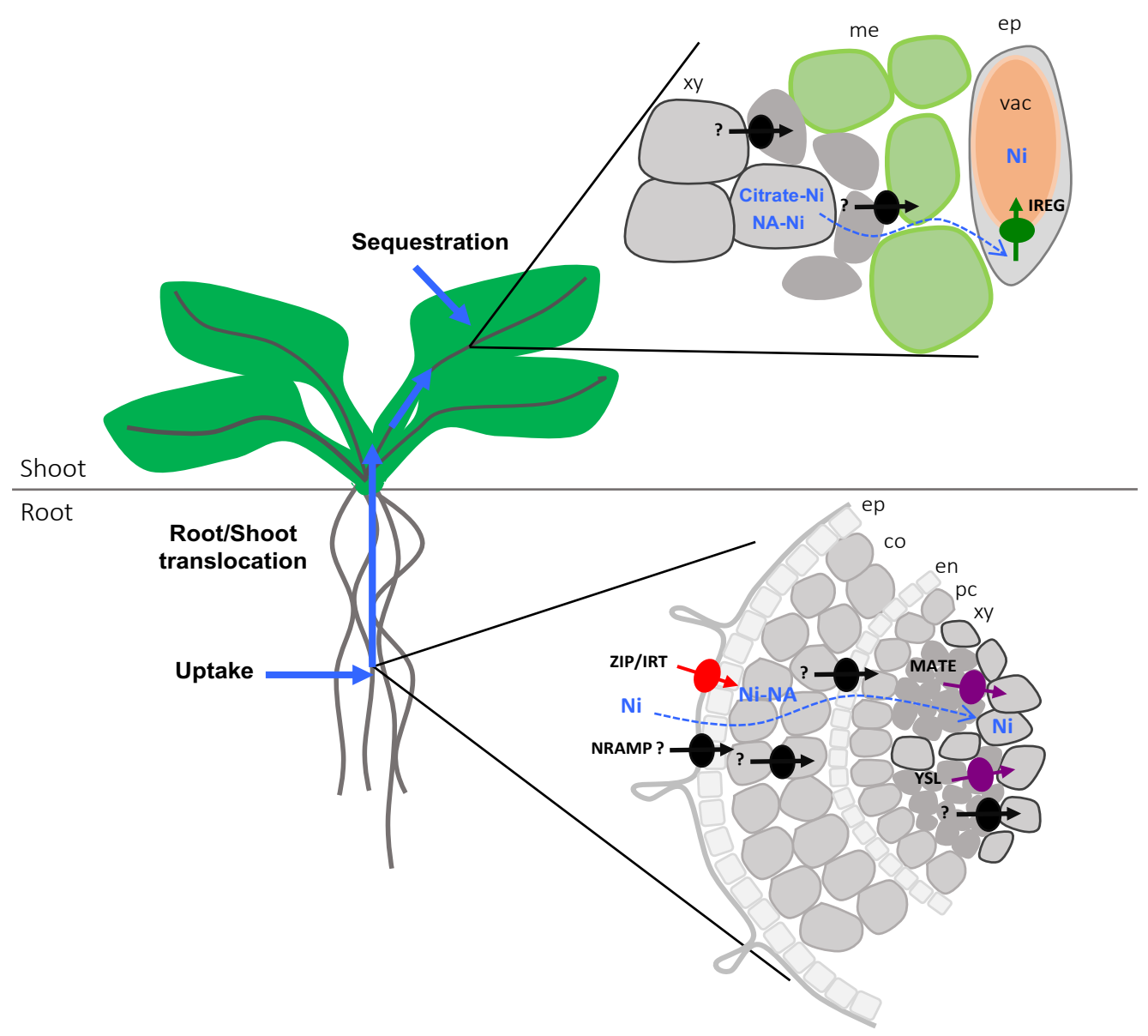

Figure 3

Figure 8.3. Proposed mechanisms of $\mathrm{Ni}$ transport in Hyperaccumulators. Efficient $\mathrm{Ni}$ uptake is mediated by metal transporters of the ZIP/IRT family and possibly other transporters such as NRAMPs located at the plasma membrane of root epidermal cells (ep). Ni is then transported through the cortex (co) and the endodermis (en) by a combination of Ni export and import transporter activities. During this step, $\mathrm{Ni}$ is chelated [e.g. by nicotianamine (Ni-NA)] to reduce its reactivity in the cytoplasm. Binding to His might prevent vacuolar sequestration to favor radial transport. In the pericycle (pc), Ni is loaded in the xylem (xy) together with chelator molecules (e.g. NA, citrate...) by YSL and MATE transporters and transported to the shoot. The mechanisms involved in xylem unloading and transport to the epidermal cell are not well known but may be similar as the one involved in Ni transport in roots. In epidermal cell, Ni is transported and stored in the vacuole (vac) by IREG transporters. Figure modified from (Hanikenne and Nouet 2011). 